\title{
Gauze and tape and transparent polyurethane dressings for central venous catheters (Review)
}

\author{
Webster J, Gillies D, O’Riordan E, Sherriff KL, Rickard CM
}

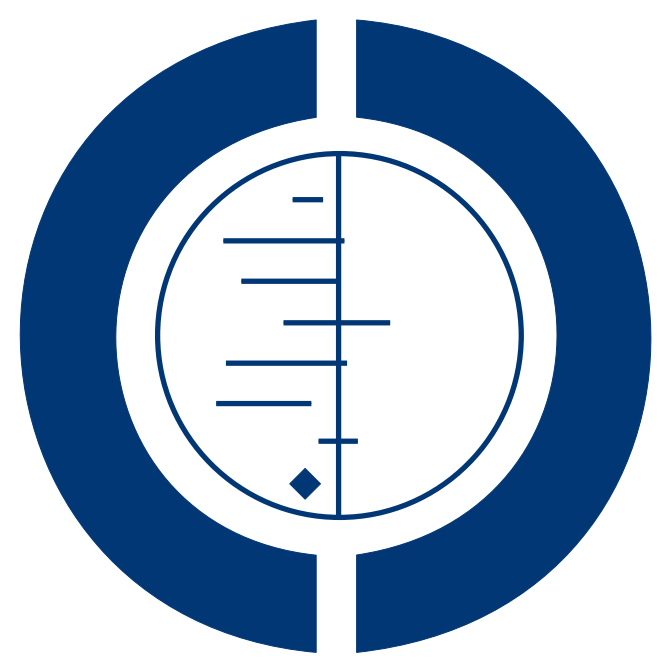

\section{THE COCHRANE COLLABORATION $^{\circledR}$}

This is a reprint of a Cochrane review, prepared and maintained by The Cochrane Collaboration and published in The Cochrane Library 2011, Issue 11

http://www.thecochranelibrary.com

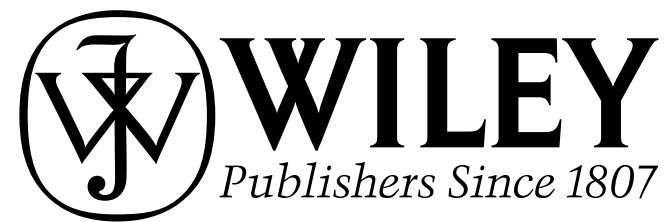

Gauze and tape and transparent polyurethane dressings for central venous catheters (Review)

Copyright (C) 20II The Cochrane Collaboration. Published by John Wiley \& Sons, Ltd. 
TABLE OF CONTENTS

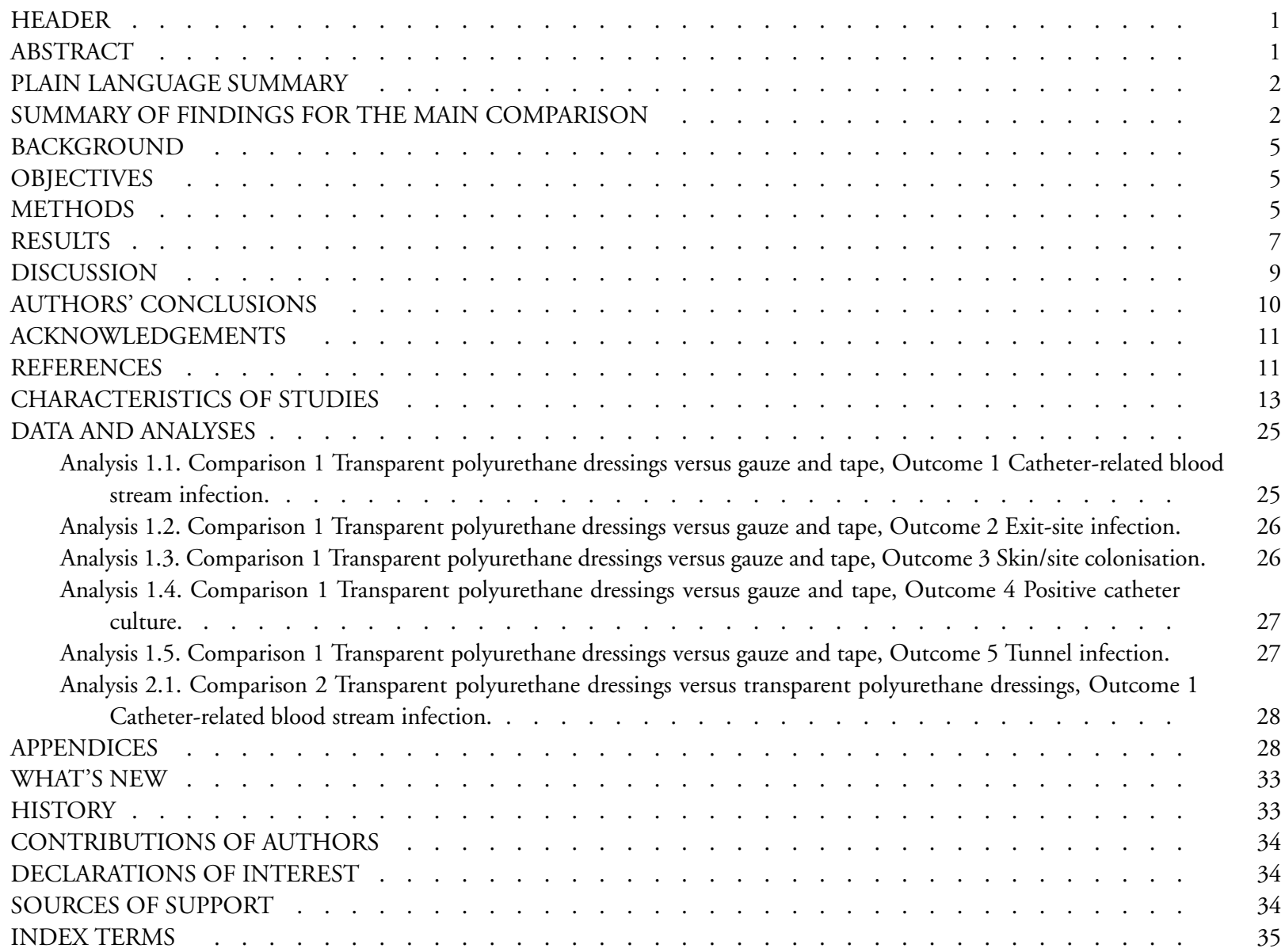

Gauze and tape and transparent polyurethane dressings for central venous catheters (Review)

Copyright (C) 20II The Cochrane Collaboration. Published by John Wiley \& Sons, Ltd. 


\title{
Gauze and tape and transparent polyurethane dressings for central venous catheters
}

\author{
Joan Webster ${ }^{1,4,5}$, Donna Gillies ${ }^{2}$, Elizabeth O’Riordan ${ }^{3}$, Karen L Sherriff ${ }^{4}$, Claire M Rickard ${ }^{4}$ \\ ${ }^{1}$ Centre for Clinical Nursing, Royal Brisbane and Women's Hospital, Brisbane, Australia. ${ }^{2}$ Sydney West Area Mental Health Service, \\ Parramatta, Australia. ${ }^{3}$ Faculty of Nursing and Midwifery, The University of Sydney and The Children's Hospital at Westmead, \\ Sydney, Australia. ${ }^{4}$ NHMRC Centre of Research Excellence in Nursing, Griffith University, Brisbane, Australia. ${ }^{5}$ School of Nursing \\ \& Midwifery, University of Queensland, Brisbane, Australia
}

Contact address: Joan Webster, joan_webster@health.qld.gov.au.

Editorial group: Cochrane Wounds Group.

Publication status and date: New search for studies and content updated (no change to conclusions), published in Issue 11, 2011.

Review content assessed as up-to-date: 9 May 2011.

Citation: Webster J, Gillies D, O'Riordan E, Sherriff KL, Rickard CM. Gauze and tape and transparent polyurethane dressings for central venous catheters. Cochrane Database of Systematic Reviews 2011, Issue 11. Art. No.: CD003827. DOI: 10.1002/14651858.CD003827.pub2.

Copyright @ 2011 The Cochrane Collaboration. Published by John Wiley \& Sons, Ltd.

\section{A B S T R A C T}

\section{Background}

Central venous catheters (CVCs) facilitate venous access, allowing the intravenous administration of complex drug treatments, blood products and nutritional support, without the trauma associated with repeated venepuncture. However, CVCs are associated with a risk of infection. Some studies have indicated that the type of dressing used with them may affect the risk of infection. Gauze and tape, transparent polyurethane film dressings such as Tegaderm ${ }^{\circledR}$ and Opsite ${ }^{\circledR}$, and highly vapour-permeable transparent polyurethane film dressings such as Opsite IV3000®, are the most common types of dressing used to secure CVCs. Currently, it is not clear which type of dressing is the most appropriate.

Objectives

To compare gauze and tape with transparent polyurethane CVC dressings in terms of catheter-related infection, catheter security, tolerance to dressing material and dressing condition in hospitalised adults and children.

\section{Search methods}

For this third update, we searched The Cochrane Wounds Group Specialised Register (10 May 2011); The Cochrane Central Register of Controlled Trials (CENTRAL; The Cochrane Library 2011, Issue 2), Ovid MEDLINE (1950 to April Week 4 2011); Ovid MEDLINE (In-Process \& Other Non-Indexed Citations, May 11, 2011); Ovid EMBASE (1980 to 2011 Week 18); and EBSCO CINAHL (1982 to 6 May 2011).

\section{Selection criteria}

All randomised controlled trials (RCTs) evaluating the effects of dressing type (e.g. gauze and tape versus transparent polyurethane dressings) on CVC-related infection, catheter security, tolerance to dressing material and dressing condition in hospitalised patients.

Data collection and analysis

Two review authors independently assessed trial quality and extracted data. We contacted study authors for missing information.

Gauze and tape and transparent polyurethane dressings for central venous catheters (Review)

Copyright $\odot 2011$ The Cochrane Collaboration. Published by John Wiley \& Sons, Ltd. 


\section{Main results}

Six studies were included in earlier versions of the review. In this update two of the previously included papers have been excluded and two new trials have been added. Of these six trials, four compared gauze and tape with transparent polyurethane dressings (total participants $=337$ ) and two compared different transparent polyurethane dressings (total participants $=126)$. Catheter-related bloodstream infection was higher in the transparent polyurethane group when compared with gauze and tape; OR 4.19 (95\%CI 1.02 to 17.23) however these small trials were at risk of bias so this evidence is graded low quality. There was no evidence of a difference between highly permeable polyurethane dressings and other polyurethane dressings in the prevention of catheter-related bloodstream infection (low quality evidence). No other significant differences were found.

\section{Authors' conclusions}

We found a four-fold increase in the rate of catheter related blood stream infection when a polyurethane dressing was used to secure the central venous catheter however this research was at risk of bias and the confidence intervals were wide indicating high uncertainty around this estimate; so the true effect could be as small as $2 \%$ or as high as 17 -fold. More, better quality research is needed regarding the relative effects of gauze and tape versus polyurethane dressings for central venous catheter sites.

\section{PLAIN LANGUAGE SUMMARY}

Different dressings used to protect the central venous catheter site with the aim of reducing the chance of developing a catheterrelated infection

A central venous catheter is a small tube inserted into a major vein to allow medications and other fluids to be 'dripped' into the body over time without repeated injections. It is used in preference to a peripheral catheter (e.g. in the hand or arm) when access is required for long periods of time, or when the fluids being administered are damaging to the tissues. However, because central catheters are open to large veins they are associated with a risk of blood infection. Several different kinds of dressing are used for protecting the central venous catheter site, including transparent polyurethane dressings, and gauze and tape. These dressings may vary in their durability, ease of use, ability to prevent infections and skin reactions. We reviewed all relevant medical trials to identify any differences between dressings, particularly with respect to differences in infection rates. We found that there were fewer catheter-related infections in the group using gauze and tape but the evidence was low quality and larger, better quality studies are needed confirm these findings. 


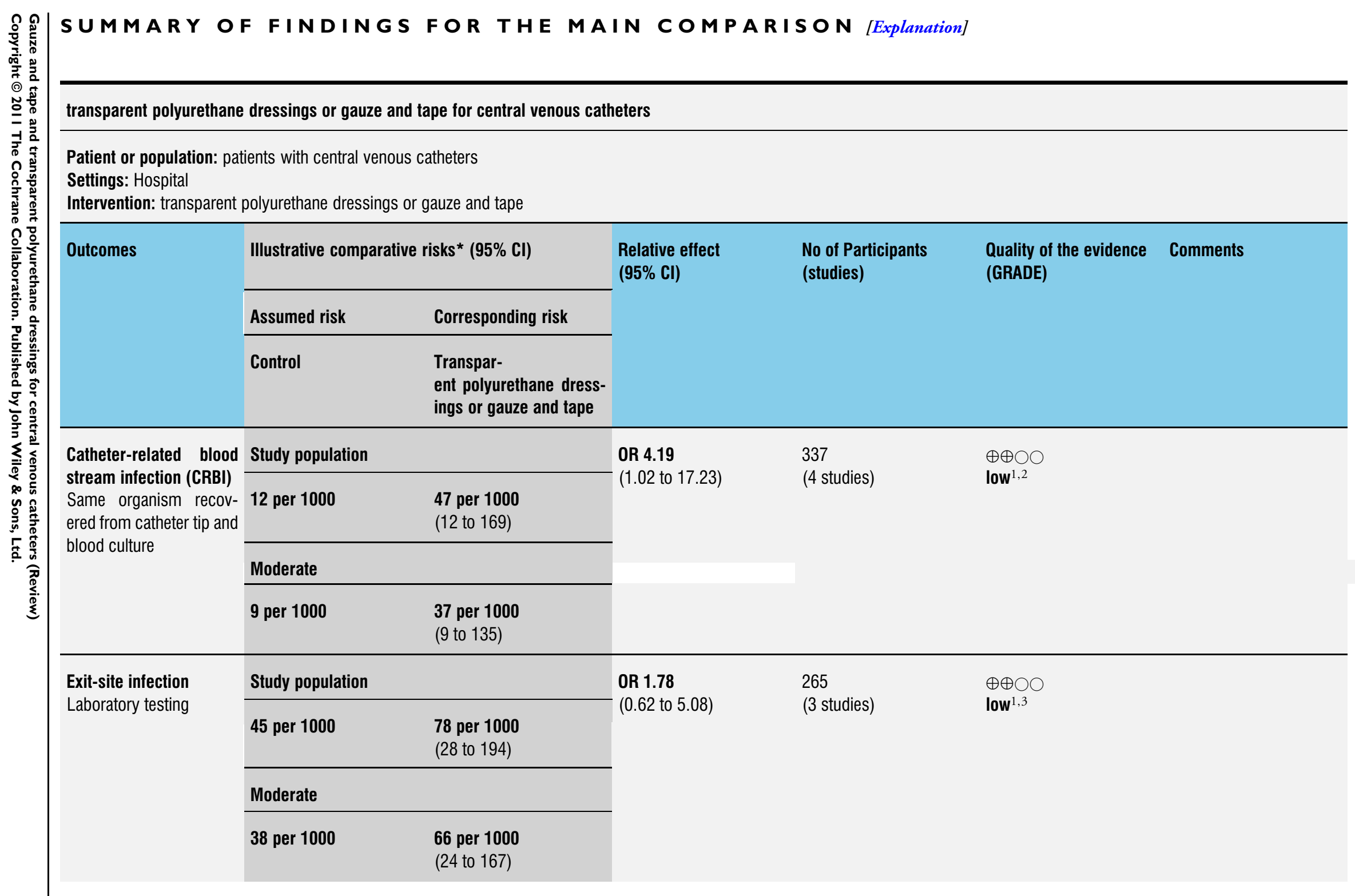




\begin{tabular}{|c|c|c|c|c|c|}
\hline \multirow{4}{*}{$\begin{array}{l}\text { Positive catheter culture } \\
\text { Laboratory testing }\end{array}$} & \multicolumn{2}{|c|}{ Study population } & \multirow{4}{*}{$\begin{array}{l}\text { OR } 0.74 \\
-(0.27 \text { to } 2.09)\end{array}$} & \multirow{4}{*}{$\begin{array}{l}138 \\
\text { (2 studies) }\end{array}$} & \multirow{4}{*}{$\begin{array}{l}\oplus \oplus \bigcirc \bigcirc \\
\text { low }^{1,4}\end{array}$} \\
\hline & 139 per 1000 & $\begin{array}{l}107 \text { per } 1000 \\
\text { (42 to 252) }\end{array}$ & & & \\
\hline & \multicolumn{2}{|l|}{ Moderate } & & & \\
\hline & 135 per 1000 & $\begin{array}{l}104 \text { per } 1000 \\
\text { (40 to 246) }\end{array}$ & & & \\
\hline
\end{tabular}

*The basis for the assumed risk (e.g. the median control group risk across studies) is provided in footnotes. The corresponding risk (and its $95 \%$ confidence interval) is based on the assumed risk in the comparison group and the relative effect of the intervention (and its $95 \% \mathrm{Cl}$ ).

CI: Confidence interval; OR: Odds ratio;

GRADE Working Group grades of evidence

High quality: Further research is very unlikely to change our confidence in the estimate of effect.

Moderate quality: Further research is likely to have an important impact on our confidence in the estimate of effect and may change the estimate.

Low quality: Further research is very likely to have an important impact on our confidence in the estimate of effect and is likely to change the estimate.

Very low quality: We are very uncertain about the estimate.

${ }^{1}$ Allocation concealment was unclear in three of the four trials. It was also unclear in three of the four trials if outcome assessment was

blinded. However, because this outcome involved laboratory analysis, it is likely that technicians were unaware of group allocation

${ }^{2}$ All of the trials were small with the largest enrolling only 101 participants. The event rate was comparatively low for CRBI with wide confidence intervals, indicating that the effect includes the possibility of higher or lower rates of CRBI.

${ }^{3}$ Small sample size. Effect includes the possibility of higher or lower rates of exit site infection.

${ }^{4}$ Small sample size. Effect includes the possibility of higher or lower rates of a positive catheter culture. 


\section{B A C K G R O U N D}

Central venous catheters (CVCs) are used increasingly within the hospital setting. The placement of a CVC in a central vein allows the intravenous administration of complex drug treatments, blood products and nutritional support without the trauma associated with repeated needle insertions (venepuncture). However, CVCs are associated with a higher incidence of bloodstream infection then peripheral catheters (Maki 2006). Organisms from the patient's skin are a major source of catheter-related infection, especially in the first one to two weeks following insertion (Mermel 2011).

Traditionally, the CVC site would be dressed with dry gauze and tape, but in the early 1980s these gave way to transparent polyurethane dressings, notably Opsite ${ }^{\circledR}$ (Smith \& Nephew Healthcare Ltd), Tegaderm ${ }^{\circledR}(3 \mathrm{M})$ and, more recently, Opsite IV3000® (Smith \& Nephew Healthcare Ltd). There are substantial differences between different transparent polyurethane dressings, including size, permeability and weight (Thomas 1988), and possible clinical advantages of increased durability, improved security of the catheter, visibility of the wound site, and provision of an effective barrier to micro-organisms. As some dressings may be more conducive to the growth of micro-organisms on the skin, the type of dressing applied to the catheter insertion site may influence the incidence of catheter-related infections (Callahan 1987; Maki 1992; Schwartz-Fulton 1981; Treston-Aurand 1997). There is concern that transparent polyurethane dressings increase skin surface humidity, which may result in increased bacterial colonisation of the site, and therefore, an increased risk of catheter-related infection (Conly 1989; Dickerson 1989; Wille 1993). Therefore, dressings such as Opsite IV3000 - a highly vapour permeable transparent polyurethane dressing (Wille 1993) - that increases the rate of evaporation of fluid from the CVC site may decrease the risk of infection.

Despite the possible risks associated with CVC dressings, there appear to be no clear recommendations regarding their suitability. The recommendations for the prevention of intravascular devicerelated infections published by the US Centers for Disease Control and Prevention direct to: "Use either sterile gauze or sterile, transparent, semipermeable dressings to cover the catheter site" (O'Grady 2011). Before embarking on the first edition of this review we searched the Cochrane Database of Systematic Reviews (CDSR) and the Database of Abstracts of Reviews of Effectiveness (DARE) to identify pre-existing reviews. No Cochrane review addressing CVC dressings was found, but a meta-analysis that compared the effects of dressing types for peripheral and central catheters was identified from DARE (Hoffmann 1992). This meta-analysis reported that the risk of catheter tip colonisation (but not catheter-related blood stream infection) was significantly increased with transparent CVC dressings compared with gauze and tape. However, this analysis of seven studies included two studies with an additional intervention in one dressing group only (Andersen 1986; Powell 1982); one study that allocated patients on the basis of where they were nursed (not randomly) (Young 1988); and one study where the data were not from a patient sample (Conly 1989). Therefore, several factors in this meta-analysis could have biased its results. Furthermore, several new studies on this topic have been published since the Hoffmann 1992 review went to press (the search date for this review went up to mid 1991), and these data needed to be evaluated.

The lack of clear evidence regarding the most appropriate dressing for CVCs established the need to undertake this systematic review. This review was undertaken to determine whether there was any difference between gauze and tape and transparent polyurethane dressings in relation to CVC-related infection, catheter security, tolerance to dressing material and dressing condition.

\section{O B J E C T I VES}

To compare gauze and tape with transparent polyurethane dressings for central venous catheters, in terms of catheter-related infection, catheter security, tolerance to dressing material and dressing condition in hospitalised adults and children.

\section{METHODS}

\section{Criteria for considering studies for this review}

\section{Types of studies}

All randomised controlled trials (RCTs) comparing the effects of gauze and tape with transparent polyurethane dressings, or comparing different transparent polyurethane dressings on CVC or skin colonisation, catheter-related bacteraemia (presence of bacteria in the blood), local or tunnel (following the route of the catheter) infection, catheter security, tolerance to dressing material and dressing condition in hospitalised patients. Studies with more than $50 \%$ loss to follow-up were excluded. Whilst we did not state explicitly in our protocol that studies where comparison arms had different co-interventions would be excluded, this was how we interpreted the protocol. We also excluded trials where the central line was peripherally inserted.

\section{Types of participants}

Patients, of any age, in the hospital setting, with CVCs in situ.

\section{Types of interventions}

Studies which compared gauze and tape CVC dressings with transparent polyurethane CVC dressings, or compare different transparent polyurethane CVC dressings. 


\section{Types of outcome measures}

\section{Primary outcomes}

- Incidence of catheter-related bloodstream infection: isolate of the same organism from a semi-quantitative or quantitative culture of a catheter segment and from separate percutaneous blood cultures, with no other identifiable source of infection.

- Incidence of positive catheter cultures: any positive semiquantitative or quantitative culture from a proximal or distal catheter segment.

- Incidence of skin/site colonisation (mean number of colony-forming units): any positive semi-quantitative or quantitative culture from the skin around the catheter site.

As these outcomes are measured by methods that have accepted validity and reliability these data will be collected from included studies even where reliability and validity were not shown.

\section{Secondary outcomes}

- Incidence of exit-site infection.

- Incidence of tunnel infection.

- Incidence of catheter security.

- Incidence of skin irritation.

- Dressing condition/durability (incidence or mean score).

Data for these outcomes were only collected from included studies if the measures used were shown to be valid and reliable. Any measure that had only face validity and had not been tested for reliability by methods such as inter-rater agreement was not considered to be valid and reliable.

\section{Search methods for identification of studies}

For the search methods used in the second update of this review see Appendix 1.

For this third update we searched the following electronic databases to find reports of relevant randomised controlled trials (RCTs):

- The Cochrane Wounds Group Specialised Register (searched 10 May 2011);

- The Cochrane Central Register of Controlled Trials (CENTRAL) (The Cochrane Library 2011, Issue 2);

- Ovid MEDLINE (1950 to April Week 4 2011);

- Ovid MEDLINE (In-Process \& Other Non-Indexed Citations, May 11, 2011);

- Ovid EMBASE (1980 to 2011 Week 18);

- EBSCO CINAHL (1982 to 6 May 2011).

We used the following search strategy in the Cochrane Central Register of Controlled Trials (CENTRAL):

\#1 MeSH descriptor Catheterization, Central Venous explode all trees
\#2 venous NEAR/3 (catheter* or line*):ti,ab,kw

\#3 central NEAR/3 (catheter* or line*):ti,ab,kw

\#4 hickman NEXT catheter*

\#5 broviac NEXT catheter*

\#6 cook NEXT catheter*

\#7 (\#1 OR \#2 OR \#3 OR \#4 OR \#5 OR \#6)

\#8 MeSH descriptor Occlusive Dressings explode all trees

\#9 (occlusive or "gauze" or "tape" or polyurethane or permeable or nonpermeable or non-permeable or transparent) NEAR/3 dressing*:ti,ab,kw

\#10 (\#8 OR \#9)

\#11 (\#7 AND \#10)

The search strategies for Ovid MEDLINE, Ovid EMBASE and EBSCO CINAHL can be found in Appendix 2; Appendix 3 and Appendix 4 respectively. The Ovid MEDLINE search was combined with the Cochrane Highly Sensitive Search Strategy for identifying randomised trials in MEDLINE: sensitivity- and precisionmaximizing version (2008 revision) (Lefebvre 2011). The Ovid EMBASE and EBSCO CINAHL searches were combined with the trial filters developed by the Scottish Intercollegiate Guidelines Network (SIGN) (SIGN 2010). There were no restrictions with respect to language, date of publication or study setting.

\section{Data collection and analysis}

\section{Selection of studies}

Two review authors assessed all potentially relevant references for eligibility. Where necessary, we obtained abstracts of potentially relevant papers or full papers in order to assess further studies for inclusion. Where differences of opinion regarding eligibility occurred, they were resolved by discussion or by referral to a third member of the team.

\section{Data extraction and management}

Two members of the review group independently extracted data from each study. Differences of opinion were resolved either by consensus or by referral to a third member of the team. If data were missing from trial reports, we contacted study authors for additional information.

Data extracted included:

- Country and setting where the study was performed.

- Inclusion and exclusion criteria.

- Details of intervention.

- Outcomes measured.

- Duration of study.

- Numbers enrolled and completing in each group.

- Baseline characteristics of each group.

- Results per group. 


\section{Assessment of risk of bias in included studies}

Two review authors independently assessed the quality of eligible trials (JW,KS) using the Cochrane Collaboration tool for assessing risk of bias (Higgins 2011). This tool addresses six specific domains, namely sequence generation, allocation concealment, blinding, incomplete outcome data, selective outcome reporting and other issues which may potentially bias the study (see Appendix 5 for details of criteria on which the judgement was based). Blinding and completeness of outcome data were assessed for each outcome separately. A risk of bias table was completed for each eligible study. Disagreements between authors were resolved by consensus or referral to a third author. We attempted to contact investigators of included trials to resolve any ambiguities. Assessment of risk of bias is presented using a 'risk of bias summary figure', which presents all the judgements in a cross-tabulation of study by entry.

\section{Measures of treatment effect}

Event rates for binary outcomes (e.g., infection rates) are presented as odds ratios (OR) and $95 \%$ confidence intervals (CI). For continuous outcomes we calculated the difference in means with $95 \%$ confidence intervals (CI). Skewed data were not used. Skew could only be defined when a scale started from zero. If the standard deviation, multiplied by two, was greater than the mean then the distribution of data was deemed to be skewed (Altman 1996).

\section{Assessment of heterogeneity}

We tested for statistical heterogeneity by performing a chi-squared test $\left(\mathrm{chi}^{2}\right)$. We assessed the extent of heterogeneity using the $\mathrm{I}^{2}$ statistic (Deeks 2011). This examines the percentage of total variation across studies due to heterogeneity rather than to chance. Values of $\mathrm{I}^{2}$ over $75 \%$ indicate a high level of heterogeneity. Where a high level of heterogeneity was found, a random-effects model was used for pooling. If the results of a random-effects analysis were substantially different from the fixed-effect analysis, the studies responsible for heterogeneity were not to be added to the main body of homogeneous trials, but were to be summarised and presented separately.

\section{Assessment of reporting biases}

Wherever possible, data from all included studies were to be entered into a funnel graph (trial effect against trial size) in an attempt to investigate the likelihood of overt publication bias (Egger 1997)

\section{Subgroup analysis and investigation of heterogeneity}

Planned sub-group analyses were:

- Adult and paediatric patients.

- Frequency of dressing changes.

\section{Sensitivity analysis}

Planned sensitivity analysis was based on concealment of allocation (allocation adequately concealed vs unclear / inadequate allocation concealment).

\section{RES U L T S}

\section{Description of studies}

See: Characteristics of included studies; Characteristics of excluded studies.

See: Characteristics of included studies and Characteristics of excluded studies for further details.

Of the 28 full papers and abstracts considered in previous versions of this review, six studies met the inclusion criteria and were included in the original review (Brandt 1996; Hägerström 1994a; Neufeld 1991; Petrosino 1988a; Shivnan 1991; Wille 1993). In this third update, 45 further references were screened, 41 of which were not relevant to this review. Two of the remaining four references were added to the review (de Barros 2009; Giles 2002), and two were excluded (Chico-Padron 2011; Olson 2008). We also excluded two of the trials included in previous versions of this review (Hägerström 1994a; Petrosino 1988a).

\section{Included studies}

Six trials, with a total of 463 participants, are included in this update. One trial was conducted in Spain (de Barros 2009), one in Turkey (Giles 2002), one in Canada (Neufeld 1991), one in the Netherlands (Wille 1993) and two in the USA (Brandt 1996; Shivnan 1991). Three acknowledged industry sponsorship (Neufeld 1991; Shivnan 1991; Wille 1993). Participants were either oncology patients (Brandt 1996; Shivnan 1991) renal patients (de Barros 2009); or general surgical patients (Giles 2002; Neufeld 1991; Wille 1993).

Two comparisons were reported in the included studies. These were gauze and tape compared with transparent polyurethane dressings (de Barros 2009; Brandt 1996; Giles 2002; Shivnan 1991) and one transparent polyurethane dressing compared with another transparent polyurethane dressing (Neufeld 1991; Wille 1993).

All the included studies reported patient data for at least one of the primary outcomes of this review (de Barros 2009; Brandt 1996; Giles 2002; Neufeld 1991; Shivnan 1991; Wille 1993), and three studies reported secondary outcomes (Brandt 1996; Neufeld 1991; Shivnan 1991). The data for dressing changes from the study by Neufeld 1991, however, were skewed and so were not added to the meta-analysis, therefore, data for secondary outcomes were available from two included studies. 
Data from four of the six included studies could be pooled: Brandt 1996, de Barros 2009; Giles 2002 and Shivnan 1991 all reported data for catheter-related bloodstream infection when gauze and tape dressings were compared with transparent polyurethane dressings; catheter tip data from the de Barros 2009 and Giles 2002 trials were also pooled.

\section{Excluded studies}

In an earlier version of this review 22 papers and abstracts from 18 trials were excluded. In summary: three trials were not RCTs (Reynolds 1987; Wheeler 1988; Young 1988); four had a co-intervention other than the dressing type in one group only (Andersen 1986; Little 1998; Nehme 1984; Powell 1982); one used gauze in both groups (Lawson 1986); it was not possible to assess whether five studies met the eligibility criteria for this review (Dickerson 1989; Freiberger 1992; Maki 1992; Ricard 1985; Thomas 1977); two trials had not assessed the validity of their outcome measurement tools (Berggren 1995; Keenlyside 1992); two trials did not report their results by group (Conly 1989; Maki 1984); four references were either duplicate publications or later versions of the same trial (Keenlyside 1993; McCredie 1984; Powell 1984; Powell 1985), and one trial was not conducted in a hospital setting (Le Corre 2003).

For this third update, two trials identified by the new search were excluded: one because the central lines were inserted peripherally (Chico-Padron 2011), and the other, because instruments used to measure outcomes had not been assessed for validity and reliability (Olson 2008). In addition, two of the trials from earlier versions of this review were also excluded. One because it was unclear if it was a RCT (Hägerström 1994); and the other because the only outcome of interest was 'infection' but it was unclear what type of infection this was. Infection was defined as a composite of a number of infection indicators (such as redness, elevated temperature, erythema, pain and skin culture), ranked according to importance (Petrosino 1988)

\section{Risk of bias in included studies}

\section{Allocation}

\section{Sequence generation}

Only two of the six trials described an adequate method for sequence generation (Giles 2002; Shivnan 1991).

\section{Allocation concealment}

An adequate method of allocation concealment was reported in only one trial (de Barros 2009).

\section{Blinding}

\section{Blinding of personnel and participants}

This was not possible in trials where gauze and tape were compared with transparent polyurethane dressings (de Barros 2009; Brandt 1996; Giles 2002; Shivnan 1991). Blinding of personnel and participants was not mentioned where one transparent polyurethane dressings was compared with another transparent polyurethane dressings (Neufeld 1991; Wille 1993).

\section{Blinding of outcome assessor}

Neufeld 1991 reported that an independent assessor conducted a blind assessment on each central line on a daily basis. In this study, the laboratory assessments were also blinded. In the Brandt 1996 trial, microbiological processing of samples was also blinded. The remaining four studies did not report on this aspect of blinding.

\section{Incomplete outcome data}

All of the included studies reported the number of patients lost to follow-up, which ranged from 0 to $40 \%$. Four trials were graded as having a low risk of reporting bias (Brandt 1996; de Barros 2009; Giles 2002; Wille 1993). Some participants in three of these trials were excluded from the analysis following randomisation and data were analysed on an 'as-treated' basis by the original trialists (Brandt 1996; Giles 2002; Wille 1993). The nature of reporting in one study made it unclear whether all participants had been included in the analyses (Shivnan 1991). For the remaining trial (Neufeld 1991;) reporting of data was incomplete, these studies were assessed as having a high risk of reporting bias.

\section{Selective reporting}

All trials provided information for all of the of outcomes prespecified in the paper (protocols were not accessed for any of the studies). None of our primary outcome measures were reported in all reports. Catheter-related bloodstream infection was reported by Brandt 1996; de Barros 2009; Giles 2002; Shivnan 1991 and Wille 1993; catheter tip colonisation by de Barros 2009 and Giles 2002; and skin colonisation by Giles 2002; Neufeld 1991 and Shivnan 1991.

\section{Other potential sources of bias}

It was difficult to determine if there were 'unit of analysis' issues in two trials where dressings, rather than participants, were randomised (Giles 2002; Neufeld 1991). In one trial of highly vulnerable oncology patients, a range of antibiotics was administered during the study period but it was unclear if antibiotic use was evenly distributed between treatment groups (Shivnan 1991). Finally, half of the trials received partial or full manufacturer sponsorship (Neufeld 1991; Shivnan 1991; Wille 1993). 


\section{Effects of interventions}

See: Summary of findings for the main comparison transparent polyurethane dressings or gauze and tape for central venous catheters

\section{Transparent polyurethane dressings compared with gauze and tape (Analysis 0I) (Summary of findings table I)}

Five outcomes were included for this comparison:

Catheter-related bloodstream infection was reported in four studies with a combined total of 337 participants (Brandt 1996; de Barros 2009; Giles 2002; Shivnan 1991). In the de Barros 2009 trial, only data for methicillin-resistant Staphylococcus aureus (MRSA) was included in this outcome. Information presented in the table for other organisms was difficult to interpret. All trials with data favoured gauze and tape and, when data were combined, there were significantly fewer infections in the gauze and tape group $(\mathrm{p}=0.05)$; (transparent polyurethane dressing $9 / 165$ and gauze and tape 2/172) (OR 4.19; 95\% CI 1.02 to 17.23 ) Analysis 1.1

Three trials (265 participants) provided data for exit site infection (Brandt 1996; de Barros 2009; Shivnan 1991). Although fewer participants in the gauze and tape group developed an exit site infection (6/133) compared with the transparent polyurethane group (10/132), the difference was not statistically significant(OR 1.78; $95 \%$ CI 0.62 to 5.08 ) (Analysis 1.2 ).

One study of 72 participants assessed skin/site colonisation (Giles 2002; Analysis 1.3); there was no statistically significant difference between groups (transparent polyurethane dressing 2/33 and gauze and tape $1 / 39$ ); OR $0.58 ; 95 \%$ CI 0.05 to 6.68 .

Both de Barros 2009 and Giles 2002 (138 participants) reported on the incidence of positive catheter cultures (Analysis 1.4). There was no statistically significant difference between groups on this measure (transparent polyurethane dressing 7/66 and gauze and tape 10/72) (OR 0.74; 95\% CI 0.27 to 2.09).

A total of 101 participants were assessed for tunnel infection in the (Brandt 1996) trial. The number of infections was similar between groups (transparent polyurethane dressing 3/48 and gauze and tape 5/53) (OR 0.64; 95\% CI 0.14 to 2.83)(Analysis 1.5).

The small number of included studies precluded the proposed subgroup analyses for adult and paediatric patients and frequency of dressing changes. Nor did we consider it necessary to conduct a sensitivity analysis. Only one investigator (de Barros 2009) reported information about allocation concealment; results for this trial were consistent with results from other trials (heterogeneity I

${ }^{2}$ between $0 \%$ to $\left.2 \%\right)$.

\section{Transparent polyurethane dressings compared with other transparent polyurethane dressings (Analysis 02)}

Wille 1993 was the only investigator to report rates of catheter- related bloodstream infection for this comparison. The incidence of catheter-related bloodstream infection was similar when one transparent polyurethane dressings (Opsite) (3/50) was compared with another transparent polyurethane dressings (Opsite 3000) (1/51) (OR 0.31; 95\% CI 0.03 to 3.12) Analysis 2.1.

No site colonisation occurred in either group when one transparent polyurethane dressings (Opsite) was compared with a different transparent polyurethane dressing (Opsite 3000) (OR not estimable). All data for this analysis came from the study by Neufeld 1991 which had a total sample size of 25 .

Although it was proposed that data from all included studies were to be entered into a funnel graph (trial effect against trial size) in an attempt to investigate the likelihood of overt publication bias (Egger 1997), this was not possible due to the small number of included studies.

\section{DISCUSSION}

\section{Summary of main results}

This systematic review compared gauze and tape with any type of polyurethane dressing designed to secure a central venous catheter. Outcomes analysed were catheter-related blood stream infection, catheter colonisation, skin/site colonisation, exit site infection and tunnel infection. Despite the relatively high number of studies identified as relevant to this review, few could be included. The major reasons for exclusion were the number of studies without adequate information, and studies where there was an intervention - apart from dressing type - that could have accounted for any differences between groups.

We found a four-fold increase in the rate of catheter related blood stream infection when a polyurethane dressing was used to secure the central venous catheter. However, the confidence intervals were wide, indicating high uncertainty around this estimate; the true effect could be as small as $2 \%$ or as high as 17 -fold. More research is needed to reduce the uncertainty around the size of the difference. Rates of catheter-related blood steam infections (between $0 \%$ and 6\%) were similar to those reported in prior research (Maki 2006), irrespective of the type of product used.

There have been suggestions that highly vapour permeable transparent polyurethane dressing may be superior to other types of transparent dressings (Wille 1993). However, a complete lack of heterogeneity in our analyses indicates that, at this stage, there is no evidence of difference between these types of dressings for the prevention of catheter-related blood stream infection.

In terms of other primary outcomes, it is impossible to draw any conclusions about the effectiveness of each of the dressing types from the included studies. This is because data for each of the analyses came from a limited number of studies, the largest of which reported data from 101 participants. Therefore, all of the 
included studies were underpowered to detect clinically important differences, should they exist. In particular, the sample sizes in the individual studies would have been too small to identify any difference in the incidence of catheter-related bloodstream infection, as statistically significant. Given the incidence of approximately $3.3 \%$ of catheter-related bloodstream infection in this review, data from approximately 2260 patients would be required to show a halving in the incidence of catheter-related bloodstream infection, and much larger numbers required to show a smaller effect size.

\section{Overall completeness and applicability of evidence}

Most of the trials included in this systematic review addressed the review's most important outcome, catheter-related bloodstream infection, albeit with very small samples. Other outcomes of clinical interest, however, such as exit site infection, positive catheter cultures, skin reaction and catheter security were poorly reported, and many could not be extracted for this review.

In terms of applicability of evidence, although the participants were drawn from oncology, haematology and general surgical cohorts, intensive care patients - who are high users of central lines were not represented in any of the trials included in the review. In addition, all outcomes were underpowered for demonstration of differences between groups, so support for external validity is low.

\section{Quality of the evidence}

Risk of bias was difficult to assess in most of the studies due to poor reporting. Only one trial supplied sufficient information for us to judge allocation concealment ( de Barros 2009), and it was unclear in most of the trials whether those assessing the outcome were blinded to intervention group. It was not possible to blind the participants or personnel to the gauze and tape intervention as dressings were dissimilar. In one trial (Shivnan 1991), more patients in the gauze group than the polyurethane group received prophylactic vancomycin when the catheter was inserted, which may have had an impact on results. Other issues involved inability to confirm evidence from authors. The Summary of findings for the main comparison therefore identifies that the evidence for the effects of these alternative dressings on catheter-related bloodstream infection, exit-site infection and positive catheter culture, is low quality. Finally, half of the trials received partial or full manufacturer sponsorship. It was not clear in these trials whether any publication restrictions had been placed upon authors.

\section{Potential biases in the review process}

Clearly described procedures were followed to prevent potential bias in the review process. A careful literature search was conducted and the methods we used are transparent and reproducible. None of the authors has any conflict of interest.

\section{Agreement or disagreement with other studies or reviews}

In their review of eight controlled clinical trials examining interventions for preventing infectious complications in haemodialysis patients with CVCs, McCann 2010 found no difference in exit site infection or catheter-related bacteraemia when polyurethane dressings were compared with gauze dressings. By contrast, Hoffmann 1992 found that use of transparent dressings to secure CVCs was associated with a higher risk of catheter tip infection (risk ratio (RR) 1.38 ; $95 \%$ CI 1.69 to 2.95 ). She also found a non-significantly higher rate of catheter-related bloodstream infection and bacteraemia in the polyurethane group. Nonetheless, the Hoffmann review was not limited to RCTs, and included data from letters, abstracts and other reports (Hoffmann 1992).

\section{A U THORS' CONCLUSIONS}

\section{Implications for practice}

The review found that gauze and tape as a dressing to secure central venous catheters was associated with lower rates of catheter-related bloodstream infection than transparent polyurethane dressings. However, individual studies included in the review were small and at risk of bias. We found no evidence of effect for either gauze and tape or polyurethane dressings in the prevention of any of the other outcomes included in this review.

\section{Implications for research}

Information about important factors such as cost, patient and clinician preference, and ease of use were not available for assessment in this review. These factors may influence choice of dressing, especially, where differences in clinical outcomes are small or unable to be demonstrated. Future primary research of CVC dressings should continue to measure catheter-related bloodstream infection and exit site infection, but should also include a formal, planned economic analysis, as well as an assessment of patient preference. Information about whether or not catheters are cuffed, and the location of catheter insertion are important, and should be included in future trials. In addition, other clinical data should be collected using standardised measures to facilitate comparisons and the application of evidence. Finally, the role of other dressings and technologies currently used to secure CVCs requires exploration. The quality of most of the evidence in this review was low and the trials were poorly reported. Following the CONSORT guidelines would add significantly to the usefulness of future trials (Schulz 2010). 


\section{ACKNOWLEDGEMENTS}

The review authors would like to thank: Cochrane Review Wounds Group referees (Marie Westwood, Finn Gottrup, Karen Cowley, Madeleine Flanagan, Allyson Lipp), Editors (Nicky Cullum, Andrea Nelson, Mieke Flour), and Statistical Advisor (Vicky Ashton) for their comments to improve the review, and Elizabeth Royle for copy editing the most recent update.

The authors would also like to acknowledge the contribution of D Carr, J Frost, R Gunning and I O'Brien who were review authors and contributed to the original review and subsequent updates, they are no longer active authors of this review.

\section{RE F E R E N C E S}

\section{References to studies included in this review}

Brandt 1996 \{published data only\}

Brandt B, DePalma J, Irwin M, Shogan J, Lucke JF. Comparison of central venous catheter dressings in bone marrow transplant recipients. Oncology Nursing Forum 1996;23(5):829-36.

de Barros 2009 \{published data only\}

Barros LFNM, Bettencourt ARC, Diccini S, Fram DS, Belasco AGS, Barbosa DA. Evaluation of two types of dressings used on central venous catheters for hemodialysis. Acta Paulista de Enfermagem 2009;22:481-6.

Giles 2002 \{published data only\}

Giles Y, Aksoy M, Tezelman S. What really affects the incidence of central venous catheter-related infections for short-term catheterization. Acta Chirurgica Belgica 2002; 102:256-8.

Neufeld 1991 \{unpublished data only\}

Neufeld M. A randomized control trial of the effectiveness of Opsite Wound versus IV3000 in maintaining an occlusive central line dressing. Master's Thesis, The School of Graduate Studies, McMaster University 1991.

Shivnan 1991 \{published data only\} Shivnan JC, McGuire D, Freedman S, Sharkazy E, Bosserman G, Larson E, et al.A comparison of transparent adherent and dry sterile gauze dressings for long-term central catheters in patients undergoing bone marrow transplant. Oncology Nursing Forum 1991;18(8):1349-56.

Wille 1993 \{published data only\}

Wille JC, Blusse van Oud Albas A, Thewessen EA. A comparison of two transparent film-type dressings in central venous therapy. Journal of Hospital Infection 1993;23(2): $113-21$.

\section{References to studies excluded from this review}

Andersen 1986 \{published and unpublished data\} Andersen PT, Herlevsen P, Schaumburg H. A comparative study of 'Op-site' and 'Nobecutan gauze' dressings for central venous line care. Journal of Hospital Infection 1986;7 (2):161-8.

Berggren 1995 \{published data only\}

Berggren E, Bernell L, Gustafsson L, Stenke L, Hast R. The evaluation of Opsite IV3000 versus tape and gauze dressings in the management of central venous catheters in oncology patients. Proceedings of the 5th European Conference on Advances in Wound Management. 1995:Abstract 291.

\section{Chico-Padron 2011 \{published data only\}}

Chico-Padrón RM, Carrión-García L, Delle-Vedove-Rosales L, González-Vargas CS, Marrero-Perera M, Medina-Chico $S$, et al.Comparative safety and costs of transparent versus gauze wound dressings in intravenous catheterization. Journal of Nursing Quality Care 2011;Mar 14: [Epub ahead of print].

Conly 1989 \{published data only\} Conly JM, Grieves K, Peters B. A prospective, randomized study comparing transparent and dry gauze dressings for central venous catheters. Journal of Infectious Diseases 1989; 159(2):310-9.

\section{Dickerson 1989 \{published data only\}} Dickerson N, Horton P, Smith S, Rose RC. Clinically significant central venous catheter infections in a community hospital: association with type of dressing. Journal of Infectious Diseases 1989;160(4):720-2.

Freiberger 1992 \{published data only\} Freiberger D, Bryant J, Marino B. The effects of different central venous line dressing changes on bacterial growth in a pediatric oncology population. Journal of Pediatric Oncology Nursing 1992;9(1):3-7.

Hägerström 1994 \{published data only\}

Hägerström M, Matthiesen K, Thuessen C. An improved dressing method for haemodialysis patients with permanent central venous catheters. Proceedings of the 4th European Conference on Advances in Wound Management. 1994: Abstract 197. 
Keenlyside 1992 \{published data only\}

Keenlyside D. Central venous catheters - a randomized comparative study of OpSite IV3000 and Tegaderm. Royal Society of Medicine Services International Congress and Symposium Series Number 1992;179:47-51.

Keenlyside 1993 \{published data only\}

Keenlyside D. Avoiding an unnecessary outcome. A comparative trial between IV3000 and a conventional film dressing to assess rates of catheter-related sepsis. Professional Nurse 1993;8(5):288-91.

Lawson 1986 \{published data only\} Lawson M, Kavanagh T, McCredie K, Marts K, Barbour N, Chandler W. Comparison of transparent dressing to paper tape dressing over central venous catheter sites. NITA 1986; 9(1):40-3.

Le Corre 2003 \{published data only\}

Le Corre I, Delorme M, Cournoyer S. A prospective, randomized trial comparing a transparent dressing and a dry gauze on the exit site of long term central venous catheters of hemodialysis patients. Journal of Vascular Access 2003;4 (2):56-61.

Little 1998 \{published data only\}

Little K, Palmer D. Central line exit sites: which dressing?. Nursing Standard 1998;12(48):42-4.

Maki 1984 \{published data only\}

Maki D, Will L. Colonization and infection associated with transparent dressings for central venous catheters - a comparative trial. Surgical Infection Society and Association for Practitioners in Infection Control. 1984.

Maki 1992 \{published data only\}

Maki DG. Infections due to infusion therapy. In: Bennett

JV, Brachman PS editor(s). Hospital Infections. Third

Edition. Boston: Little, Brown and Company, 1992: 849-91.

McCredie 1984 \{published data only\}

McCredie KB, Lawson M, Marts K, Stern RN. A comparative evaluation of transparent dressings and gauze dressings for central venous catheters. Journal of Parenteral \& Enteral Nutrition 1984;8(1):96.

Nehme 1984 \{published data only\}

Nehme AE, Trigger JA. Catheter dressings in central parenteral nutrition: A prospective randomized comparative study. Nutritional Support Services 1984;49:42-50.

Olson 2008 \{published data only\}

Olson C, Heilman BS. Clinical performance of a new transparent chlorhexidine gluconate central venous catheter dressing. Journal of the Association of Vascular Access. 2008; 13:13-9.

Petrosino 1988 \{published data only\}

Petrosino B, Becker H, Christian B. Infection rates in central venous catheter dressings. Oncology Nursing Forum 1988;15(6):709-17.

Powell 1982 \{published data only\}

Powell C, Regan C, Fabri PJ, Ruberg RL. Evaluation of Opsite catheter dressings for parenteral nutrition: a prospective, randomized study. JPEN. Journal of Parenteral and Enteral Nutrition 1982;6(1):43-6.

Powell 1984 \{published data only\}

Powell C, Fabri PJ, Traetow MJ, Ruberg RL. TPN catheter sepsis - Effect of Opsite. JPEN. Journal of Parenteral and Enteral Nutrition 1984;8(1):Abstract 75.

Powell 1985 \{published data only\}

Powell CR, Traetow MJ, Fabri PJ, Kudsk KA, Ruberg RL. Op-Site dressing study: a prospective randomized study evaluating povidone iodine ointment and extension set changes with 7-day Op-Site dressings applied to total parenteral nutrition subclavian sites. JPEN. Journal of Parenteral and Enteral Nutrition 1985;9(4):443-6.

Reynolds 1987 \{published data only\}

Reynolds MG, Tebbs SE, Elliott TS. Do dressings with increased permeability reduce the incidence of central venous catheter related sepsis?. Intensive and Critical Care Nursing 1987;13(1):26-9.

\section{Ricard 1985 \{published data only\}}

Ricard P, Martin R, Marcoux JA. Protection of indwelling vascular catheters:incidence of bacterial contamination and catheter-related sepsis. Critical Care Medicine. 1985;13(7): 541-3.

Thomas 1977 \{published data only\}

Thomas M. Op-site wound dressing for subclavian line care. JPEN. Journal of Parenteral and Enteral Nutrition 1977; 1:abstract 41.

Wheeler 1988 \{published data only\}

Wheeler WE, Messner R, Stephens N. A comparison of transparent dressings and gauze dressings for singlelumen, nontunneled central parenteral nutritional catheters. Nutritional Support Services 1988;8(9):27-8.

Young 1988 \{published data only\} Young GP, Alexeyeff M, Russell DM, Thomas RJ. Catheter sepsis during parenteral nutrition: The safety of long-term OpSite dressings. JPEN. Journal of Parenteral and Enteral Nutrition 1988;12(4):365-70.

\section{Additional references}

Altman 1996

Altman DG, Bland JM. Detecting skewness from summary information. BMJ 1996;313(7066): 1200 .

\section{Callahan 1987}

Callahan JL, Wesorick B. Bacterial growth under a transparent dressing. American Journal of Infection Control 1987;15(6):231-7.

\section{Deeks 2011}

Deeks JJ, Higgins JPT, Altman DG, on behalf of the Cochrane Statistical Methods Group and the Cochrane Bias Methods Group (Editors). Chapter 9: Analysing data and undertaking meta-analyses. In: Higgins JPT, Green S (editors). Cochrane Handbook for Systematic Reviews of Interventions Version 5.1.0 [updated March 2011]. The Cochrane Collaboration, 2011. Available from www.cochrane-handbook.org. 
Egger 1997

Egger M, Smith GD, Schneider M, Minder C. Bias in meta-analysis detected by a simple, graphical test. $B M J$ 1997;315(7109):629-34.

\section{Higgins 2011}

Higgins JPT, Altman DG, on behalf of the Cochrane Statistical Methods Group and the Cochrane Bias Methods Group (Editors). Chapter 8: Assessing risk of bias in included studies. In: Higgins JPT, Green $S$ (editors). Cochrane Handbook for Systematic Reviews of Interventions Version 5.1.0 [updated March 2011]. The Cochrane Collaboration, 2011. Available from www.cochrane-handbook.org. Wiley-Blackwell, 2008.

\section{Hoffmann 1992}

Hoffmann KK, Weber DJ, Samsa GP, Rutala WA. Transparent polyurethane film as an intravenous catheter dressing: A meta-analysis of the infection risks. JAMA 1992;267(15):2072-6.

\section{Lefebvre 2011}

Lefebvre C, Manheimer E, Glanville J, on behalf of the Cochrane Information Retrieval Methods Group. Chapter 6: Searching for studies. In: Higgins JPT, Green $S$ (editors). Cochrane Handbook for Systematic Reviews of Interventions Version 5.1.0 [updated March 2011]. The Cochrane Collaboration, 2011. Available from www.cochrane-handbook.org.

\section{Maki 2006}

Maki DG, Kluger DM, Crnich CJ. The risk of bloodstream infection in adults with different intravascular devices: A systematic review of 200 published prospective studies. Mayo Clinic Proceedings 2006;81:1159-71.

\section{McCann 2010}

McCann M, Moore ZE. Interventions for preventing infectious complications in haemodialysis patients with central venous catheters. Cochrane Database of
Systematic Reviews 2010, Issue 1. [DOI: 10.1002/ 14651858.CD006894.pub2]

\section{Mermel 2011}

Mermal LA. What is the predominant source of intracascular catheter infections?. Clinical Infectious Diseases 2011;52: 211-2.

\section{O'Grady 2011}

O'Grady NP, Alexander M, Burns LA, Dellinger EP, Garland J, Heard SO, et al.Healthcare Infection Control Practices Advisory Committee. Guidelines for the prevention of intravascular catheter-related infections. American Journal of Infection Control 2011;239(4 Suppl 1):S1-34.

\section{Schulz 2010}

Schulz KF, Altman DG, Moher D, CONSORT Group. CONSORT 2010 statement: Updated guidelines for reporting parallel group randomised trials. Annals of Internal Medicine 2010;152:726-32.

\section{Schwartz-Fulton 1981}

Schwartz-Fulton J, Colley R, Valanis B, Fischer JE. Hyperalimentation dressings and skin flora. NITA 1981;4: 354-7.

\section{SIGN 2010}

Scottish Intercollegiate Guidelines Network (SIGN). Search filters. http://www.sign.ac.uk/methodology/filters.html\# random (accessed 8 September 2010).

\section{Thomas 1988}

Thomas S. Comparative review of the properties of six semipermeable film dressings. Pharmaceutical Journal 1988; 240(6487):785-9.

\section{Treston-Aurand 1997}

Treston-Aurand J, Olmsted RN, Allen-Bridson K, Craig CP. Impact of dressing materials on central venous catheter infection rates. Journal of Intravenous Nursing 1997;20(4): 201-6.

* Indicates the major publication for the study 
CHARACTERISTICS OF STUDIES

Characteristics of included studies [ordered by study ID]

Brandt 1996

\begin{tabular}{ll} 
Methods & $\begin{array}{l}\text { RCT of gauze and tape vs highly-permeable transparent polyurethane dressing (Opsite } \\
\text { IV3000) }\end{array}$ \\
\hline Participants & $\begin{array}{l}\text { Included: } 101 \text { patients at least } 18 \text { years old; having a tunnelled CVC inserted after } \\
\text { admission for an autologous BMT. BMT unit of a regional oncology centre, USA. } \\
\text { Excluded: patients who had catheter-related bloodstream infection within 14 days of } \\
\text { study entry or patients with short term CVCs } \\
\text { Time in study: approximately 22 days. }\end{array}$ \\
\hline Interventions & $\begin{array}{l}\text { Group 1: gauze and tape (daily change); } \\
\text { Group 2: Opsite IV3000 (weekly change). }\end{array}$ \\
\hline Outcomes & Catheter-related bloodstream infection, exit site infection, tunnel infection \\
\hline Notes &
\end{tabular}

Notes

Risk of bias

\begin{tabular}{|c|c|c|}
\hline Bias & Authors' judgement & Support for judgement \\
\hline $\begin{array}{l}\text { Random sequence generation (selection } \\
\text { bias) }\end{array}$ & Unclear risk & $\begin{array}{l}\text { "subjects randomly were assigned to one of } \\
\text { the following CVC dressing protocols: ..." } \\
\text { Comment: randomisation procedure not } \\
\text { reported. }\end{array}$ \\
\hline Allocation concealment (selection bias) & Unclear risk & $\begin{array}{l}\text { Not reported. } \\
\text { Comment: it was unclear from the study } \\
\text { report if allocation was concealed }\end{array}$ \\
\hline
\end{tabular}

Blinding (performance bias and detection High risk bias)

Evidence for participants: not stated.

All outcomes

Comment: not possible due to the nature of the intervention (two dressings with different appearances)

Evidence for personnel: not stated.

Comment: not possible due to the nature of the intervention (two dressings with different appearances)

Blinding (performance bias and detection Unclear risk bias)

Evidence for outcomes: nursing staff obtained cultures; "investigators recorded the organisms isolated in all cultures obtained while patients remained on study"

Comment: it was unclear from the study report if the outcome assessor was blinded 
Brandt 1996 (Continued)

\begin{tabular}{|c|c|c|}
\hline $\begin{array}{l}\text { Incomplete outcome data (attrition bias) } \\
\text { All outcomes }\end{array}$ & Low risk & $\begin{array}{l}\text { "Four patients (two Gauze and tape, two } \\
\text { Opsite IV3000) with histories of pre-BMT } \\
\text { skin sensitivity (e.g., secondary to drug } \\
\text { rash, radiation skin reaction, abrasion) re- } \\
\text { quired an alternative dressing early after ac- } \\
\text { crual and were taken off study." } \\
\text { Comment: Four participants ( } 2 \text { from each } \\
\text { group who had skin reactions to the trial } \\
\text { product) were removed from the study after } \\
\text { randomisation. Analysis was per-protocol } \\
\text { rather than intention to treat (ITT). We } \\
\text { subsequently conducted an ITT analysis, } \\
\text { and results remained essentially the same }\end{array}$ \\
\hline Selective reporting (reporting bias) & Low risk & $\begin{array}{l}\text { All of the paper's pre-specified outcomes } \\
\text { were reported (protocol not accessed) }\end{array}$ \\
\hline Other bias & High risk & $\begin{array}{l}\text { More frequent dressings than specified in } \\
\text { protocol in Opsite IV } 3000 \text { group; } 2 \text { ad- } \\
\text { ditional dressing changes in the Opsite } \\
\text { IV } 3000 \text { group in week one ( } 21 \%) \text {, and } \\
\text { in week two ( } 31 \%) \text {. Additional dressing } \\
\text { changes in dry sterile gauze dressing group } \\
\mathrm{n}=15 \\
\text { "The high incidence of subjects in the } \\
\text { experimental dressing protocol requiring } \\
\text { more frequent dressing changes than spec- } \\
\text { ified in the protocol limits the conclusions } \\
\text { about exclusive effect of the assigned dress- } \\
\text { ing on the development of CVC infection" }\end{array}$ \\
\hline
\end{tabular}

de Barros 2009

\begin{tabular}{l|l} 
Methods & RCT of gauze and tape vs transparent polyurethane dressing (Tegaderm IV) \\
\hline Participants & $\begin{array}{l}\text { Included: } 66 \text { patients with end-stage renal disease, undergoing haemodialysis (33 in each } \\
\text { group), in dialysis unit in a hospital in Sao Paulo, Brazil } \\
\text { Excluded: patients with acute renal failure undergoing femoral venous catheterization }\end{array}$ \\
\hline Interventions & $\begin{array}{l}\text { Group 1: sterile gauze and micropore changed each dialysis session } \\
\text { Group 2: sterile transparent film } 8.5 \mathrm{~cm} \times 10.5 \mathrm{~cm} \text { (Tegaderm IV) changed every } 7 \text { days, } \\
\text { or as needed } \\
\text { Both groups: catheter insertion site disinfected with } 10 \% \text { alcoholic povidone-iodine } \\
\text { solution }\end{array}$ \\
\hline Outcomes & Catheter-related bloodstream infection, positive catheter culture, exit site infection
\end{tabular}




\begin{tabular}{l} 
Notes \\
$\begin{array}{l}\text { In the outcomes table, we have assumed that 'infection' is exit site infection. Bacteraemia } \\
\text { and catheter tip infection were listed separately and exit site infection was one of the } \\
\text { defined study outcomes. Attempts to clarify this point with the study author were un- } \\
\text { successful }\end{array}$ \\
\hline
\end{tabular}

\section{Risk of bias}

\begin{tabular}{|c|c|c|}
\hline Bias & Authors' judgement & Support for judgement \\
\hline $\begin{array}{l}\text { Random sequence generation (selection } \\
\text { bias) }\end{array}$ & Unclear risk & $\begin{array}{l}\text { "A random list of dressings was used to di- } \\
\text { vide } 66 \text { patients in two groups ( } 33 \text { in group } \\
1 \text { and } 33 \text { in group } 2 \text { )“. } \\
\text { Comment: it was unclear from the study } \\
\text { report what method had been used to gen- } \\
\text { erate the randomisation sequence }\end{array}$ \\
\hline Allocation concealment (selection bias) & Low risk & $\begin{array}{l}\text { "The sequences of dressings were kept in } \\
\text { a locked envelope. If the patient was eli- } \\
\text { gible for the study, the envelope contain- } \\
\text { ing dressing sequences was open and the } \\
\text { following indicated intervention was per- } \\
\text { formed:" }\end{array}$ \\
\hline
\end{tabular}

Blinding (performance bias and detection High risk bias)

All outcomes
Evidence for participants: not stated.

Comment: not possible due to the nature of the intervention (two dressings with different appearances)

Evidence for personnel: not stated.

Comment: not possible due to the nature of the intervention (two dressings with different appearances)

Evidence for outcomes: not stated. Comment: it was unclear from the study report if the outcome assessor was blinded

All outcomes

Incomplete outcome data (attrition bias) Low risk All outcomes

"There were no losses to follow up." Comment: attrition and missing data reported as nil. ITT analysis can be assumed

Selective reporting (reporting bias) Low risk

All of the paper's pre-specified outcomes were reported (protocol not accessed)

Other bias Low risk

No other potential threats to validity identified. 
Giles 2002

\begin{tabular}{l|l}
\hline Methods & RCT of gauze and tape vs transparent polyurethane dressing (brand not disclosed) \\
\hline Participants & $\begin{array}{l}\text { Included: } 70 \text { patients undergoing surgical procedures for various benign or malignant } \\
\text { gastrointestinal disorders } \\
\text { Excluded: not stated. }\end{array}$ \\
\hline Interventions & $\begin{array}{l}\text { Group 1: sterile gauze and tape changed every day and the insertion site cleaned with } \\
10 \% \text { povidone-iodine solution } \\
\text { Group 2: sterile, transparent occlusive dressing. Catheter site inspected daily but dressing } \\
\text { not changed for } 7 \text { days unless there were signs of local inflammation } \\
\text { Both groups: catheter insertion site disinfected with } 10 \% \text { povidone-iodine solution }\end{array}$ \\
\hline Outcomes & Catheter-related bloodstream infection, positive skin culture, positive tip culture \\
\hline Notes & $\begin{array}{l}\text { At the start of the study, } 70 \text { patients with } 72 \text { CVCs were included - possible 'unit of } \\
\text { analysis' issue }\end{array}$ \\
\hline
\end{tabular}

\section{Risk of bias}

\begin{tabular}{|c|c|c|}
\hline Bias & Authors' judgement & Support for judgement \\
\hline $\begin{array}{l}\text { Random sequence generation (selection } \\
\text { bias) }\end{array}$ & Low risk & $\begin{array}{l}\text { "...catheter insertion site care was done fol- } \\
\text { lowing two different methods according to } \\
\text { the number patient on the random table" }\end{array}$ \\
\hline Allocation concealment (selection bias) & Unclear risk & $\begin{array}{l}\text { "according to the number patient on the } \\
\text { random table". } \\
\text { Comment: possibly not concealed. }\end{array}$ \\
\hline $\begin{array}{l}\text { Blinding (performance bias and detection } \\
\text { bias) } \\
\text { All outcomes }\end{array}$ & High risk & $\begin{array}{l}\text { Evidence for participants: not stated. } \\
\text { Comment: not possible due to the nature } \\
\text { of the intervention (two dressings with dif- } \\
\text { ferent appearances) } \\
\text { Evidence for personnel: not stated. } \\
\text { Comment: not possible due to the nature } \\
\text { of the intervention (two dressings with dif- } \\
\text { ferent appearances) }\end{array}$ \\
\hline $\begin{array}{l}\text { Blinding (performance bias and detection } \\
\text { bias) } \\
\text { All outcomes }\end{array}$ & Low risk & $\begin{array}{l}\text { Evidence for outcomes: laboratory based. } \\
\text { Comment: assumption made they were } \\
\text { probably blinded. }\end{array}$ \\
\hline $\begin{array}{l}\text { Incomplete outcome data (attrition bias) } \\
\text { All outcomes }\end{array}$ & Low risk & $\begin{array}{l}\text { "Of } 76 \text { CVCs inserted in } 74 \text { patients, four } \\
\text { were excluded from the study:- one pa- } \\
\text { tient died on the second postoperative day, } \\
\text { tip culture was not available in one and } \\
\text { the remaining two catheters were occluded } \\
\text { shortly after insertion." } \\
\text { Comment: Analysis was per-protocol }\end{array}$ \\
\hline
\end{tabular}


Giles 2002 (Continued)

\begin{tabular}{|c|c|c|}
\hline & & $\begin{array}{l}\text { rather than intention to treat. We subse- } \\
\text { quently conducted an ITT analysis, and re- } \\
\text { sults remained essentially the same }\end{array}$ \\
\hline Selective reporting (reporting bias) & Low risk & $\begin{array}{l}\text { All of the paper's pre-specified outcomes } \\
\text { were reported (protocol not accessed) }\end{array}$ \\
\hline Other bias & High risk & $\begin{array}{l}\text { A co-intervention was used in the gauze } \\
\text { and tape group (daily cleansing with } 10 \% \\
\text { povidone iodine), making it difficult to de- } \\
\text { termine which intervention was effective } \\
\text { The unit of analysis in this study was the } \\
\text { catheter ( } 70 \text { patients with } 72 \text { CVCs were } \\
\text { included) - probable 'unit of analysis' issue }\end{array}$ \\
\hline
\end{tabular}

Neufeld 1991

Methods

RCT of transparent polyurethane dressing (Opsite) vs highly-permeable transparent polyurethane dressing (Opsite IV3000)

Participants

Included: 25 adult medical/surgical inpatients with percutaneous or tunnelled central lines in place for $>48 \mathrm{~h}$.

Excluded: oncology and haematology patients.

Time in study: at least $48 \mathrm{~h}$.

Interventions

Group 1: Opsite (changed weekly or PRN);

Group 2: Opsite IV3000 (changed weekly or PRN).

Outcomes

Site colonisation, no of dressings changed per week.

Dressing data were skewed, so not used for meta-analysis.

Catheter-related bloodstream infection.

Notes

Randomisation was by 'line', not person. Unit analysis issue for most outcomes

Risk of bias

\begin{tabular}{|c|c|c|}
\hline Bias & Authors' judgement & Support for judgement \\
\hline $\begin{array}{l}\text { Random sequence generation (selection } \\
\text { bias) }\end{array}$ & Unclear risk & $\begin{array}{l}\text { "Consecutive eligible patients were ran- } \\
\text { domised using a previously established ran- } \\
\text { domisation technique to receive either Op- } \\
\text { Site Wound and dressing change proto- } \\
\text { col...or I.V.3000 and dressing change pro- } \\
\text { tocol.." } \\
\text { Comment: it was unclear from the study } \\
\text { report what method had been used to gen- } \\
\text { erate the randomisation sequence }\end{array}$ \\
\hline
\end{tabular}


Neufeld 1991 (Continued)

\begin{tabular}{|l|l|l|l|l}
\hline Allocation concealment (selection bias) & Unclear risk & $\begin{array}{l}\text { Not reported. } \\
\text { Comment: it was unclear from the study } \\
\text { report if allocation was concealed }\end{array}$ \\
\hline $\begin{array}{l}\text { Blinding (performance bias and detection } \\
\text { bias) } \\
\text { All outcomes }\end{array}$ & High risk & $\begin{array}{l}\text { Evidence for participants: not stated. } \\
\text { Comment: not possible due to the nature } \\
\text { of the intervention (two dressings with dif- } \\
\text { ferent appearances) } \\
\text { Evidence for personnel: not stated. } \\
\text { Comment: not possible due to the nature } \\
\text { of the intervention (two dressings with dif- } \\
\text { ferent appearances) }\end{array}$ \\
\hline
\end{tabular}

Blinding (performance bias and detection Low risk bias)

All outcomes

All outcomes
High risk

(20)

"An independent assessor conducted a blind assessment on each central line dressing on a daily basis... The nurse researcher was unaware of which colour tab was indicative of which dressing, and was therefore unaware of which dressing was in the experimental or control group"

44 lines randomised; 25 lines included in analysis. ITT analysis not used. "Forty-four lines were randomised. Twenty five lines were included in the study. Nineteen lines were excluded. Reasons for exclusion were: nine lines were removed prior to the 48 hours post insertion initial site inspection. Five patients ( 6 lines) expired prior to the 48 hour initial site inspection; two lines were dropped from the study because the wrong dressing protocol was used; and one patient who had two central lines was transferred to another hospital prior to the initial site inspection"

Selective reporting (reporting bias) Low risk

All of the paper's pre-specified outcomes were reported. (Masters thesis protocol not accessed.)

Other bias

High risk
Evidence: "variety of skill and number of nurses performing central line dressings... nurses were not tested to ensure protocol compliance"

Comment: consider possible effect due to variances in dressing techniques

Evidence: "absence of a pigtail on the single lumen central line required twice the 
Neufeld 1991 (Continued)

\begin{tabular}{|l} 
number of dressing changes than the two \\
and three pigtail central lines combined. Al- \\
though lines were randomised to the con- \\
trol or experimental group, the type of line \\
was not stratified to either the control or \\
experimental group. The numbers for the \\
type of line used were therefore not equally \\
distributed and the numbers were too small \\
to ascertain specific factors related to num- \\
ber of times dressings were changed in the \\
no pigtail lines." \\
Comment: unequal distribution amongst \\
groups may have affected results \\
The unit of analysis in this study was the \\
catheter (unclear how many participants \\
were included) - probable 'unit of analysis \\
issue \\
Industry-sponsored, unclear if any con- \\
straints imposed on results
\end{tabular}

Shivnan 1991

Methods RCT of gauze and tape vs transparent polyurethane dressing (Tegaderm)

$\begin{array}{ll}\text { Participants } & \text { Included: } 71 \text { patients aged 5-56 years with a pre-existing CVC undergoing BMT for } \\ \text { malignant or immunological disorders. } \\ \text { Excluded: patients who preferred gauze dressings or had reaction to Tegaderm or tape. } \\ \text { Time in study: 26-30 days. }\end{array}$

Interventions $\quad$ Group 1: gauze and tape (replaced daily).

Group 2: Tegaderm (replaced every 4 days).

\begin{tabular}{l|l}
\hline Outcomes & Catheter-related bloodstream infection, site colonisation, exit site infection \\
\hline Notes &
\end{tabular}

Risk of bias

\begin{tabular}{l|l|l}
\hline Bias & Authors' judgement & Support for judgement \\
\hline $\begin{array}{l}\text { Random sequence generation (selection } \\
\text { bias) }\end{array}$ & Low risk & $\begin{array}{l}\text { Block randomisation within each stratum. } \\
\text { Comment: language used in the meth- } \\
\text { ods section suggests that the allocation se- } \\
\text { quence was most likely computer generated }\end{array}$ \\
\hline Allocation concealment (selection bias) & Unclear risk & $\begin{array}{l}\text { Not reported. Use of block sequencing may } \\
\text { have enabled some prediction of group allo- } \\
\text { cation if personnel aware of block arrange- }\end{array}$
\end{tabular}


Shivnan 1991 (Continued)

\begin{tabular}{|c|c|c|}
\hline & & $\begin{array}{l}\text { ment and could identify remaining alloca- } \\
\text { tions per block }\end{array}$ \\
\hline $\begin{array}{l}\text { Blinding (performance bias and detection } \\
\text { bias) } \\
\text { All outcomes }\end{array}$ & High risk & $\begin{array}{l}\text { Evidence for participants: not stated. } \\
\text { Comment: not possible due to the nature } \\
\text { of the intervention (two dressings with dif- } \\
\text { ferent appearances) } \\
\text { Evidence for personnel: not stated. } \\
\text { Comment: not possible due to the nature } \\
\text { of the intervention (two dressings with dif- } \\
\text { ferent appearances) }\end{array}$ \\
\hline $\begin{array}{l}\text { Blinding (performance bias and detection } \\
\text { bias) } \\
\text { All outcomes }\end{array}$ & Unclear risk & $\begin{array}{l}\text { Not reported. } \\
\text { Comment: it was unclear from the study } \\
\text { report if the outcome assessor was blinded }\end{array}$ \\
\hline $\begin{array}{l}\text { Incomplete outcome data (attrition bias) } \\
\text { All outcomes }\end{array}$ & Unclear risk & $\begin{array}{l}\text { "Five individuals did not complete the } \\
\text { study because of unexpected discharge or } \\
\text { transfer from the unit }(\mathrm{n}=3) \text { or because } \\
\text { of dissatisfaction with the assigned dressing } \\
(\mathrm{n}=2) \text {." } \\
\text { Unclear whether drop outs were accounted } \\
\text { for in analysis; "although skin cultures were } \\
\text { collected from all of the subjects, difficul- } \\
\text { ties in laboratory quality control allowed } \\
\text { analysis of only the first } 75 \text { subjects" }\end{array}$ \\
\hline Selective reporting (reporting bias) & Low risk & $\begin{array}{l}\text { All of the paper's pre-specified outcomes } \\
\text { were reported (protocol not accessed) }\end{array}$ \\
\hline Other bias & High risk & $\begin{array}{l}\mathrm{n}=27 \text { patients changed from assigned } \\
\text { dressing. } \\
\text { "prophylactic course of vancomycin ad- } \\
\text { ministered to some patients at the time of } \\
\text { catheter insertion" } \\
\text { Industry-sponsored in part, unclear if any } \\
\text { constraints imposed on results }\end{array}$ \\
\hline
\end{tabular}

\section{Wille 1993}

\section{Methods}

Participants
RCT of transparent polyurethane dressing (Opsite) vs highly-permeable transparent polyurethane dressing (Opsite IV3000)

Included: 101 patients $>16$ years, hospitalised for major elective surgery and scheduled to have a single lumen CVC in a newly created site. A district general hospital, Netherlands. Excluded: not stated.

Time in study: up to 21 days. 
Wille 1993 (Continued)

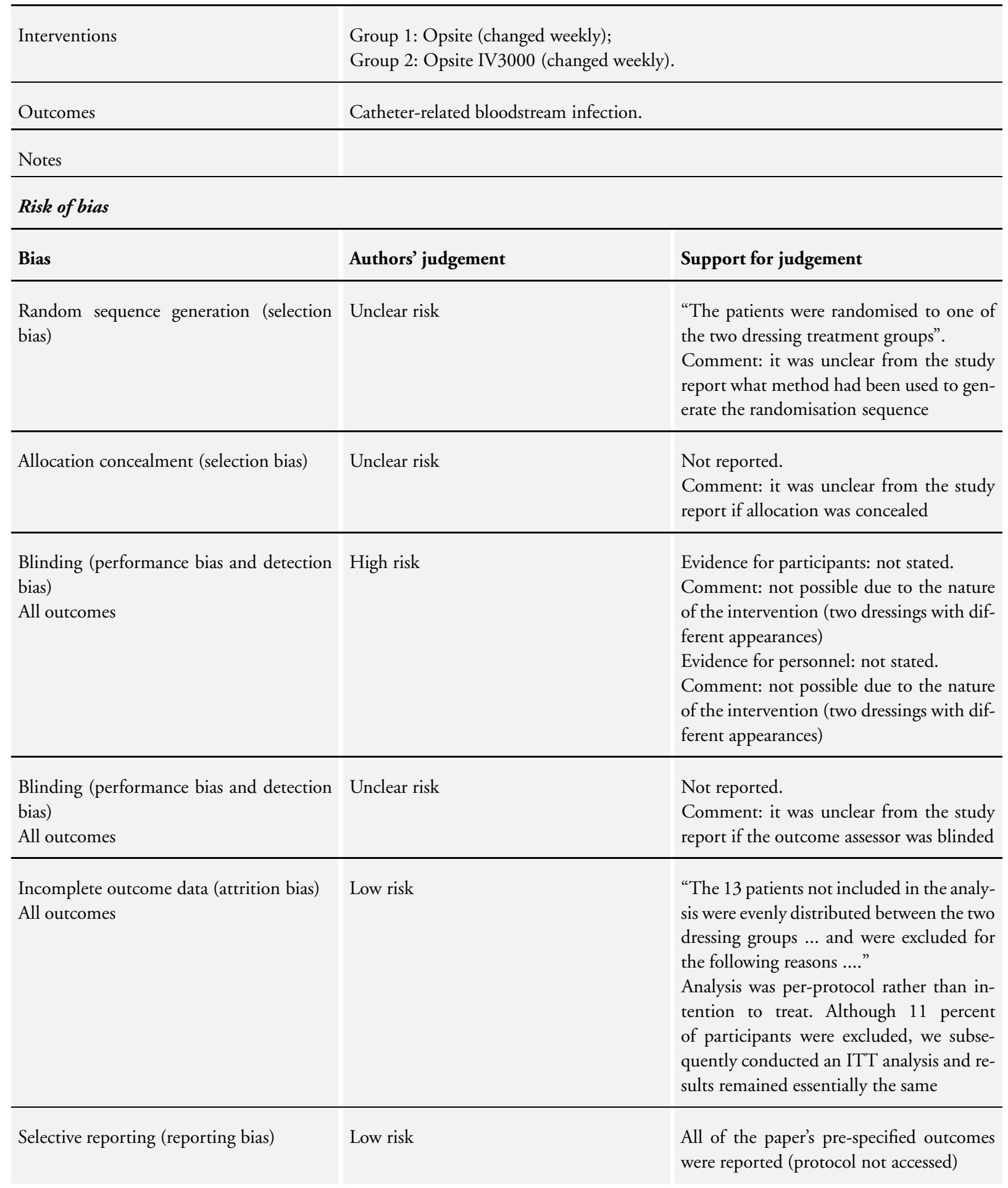


Wille 1993 (Continued)

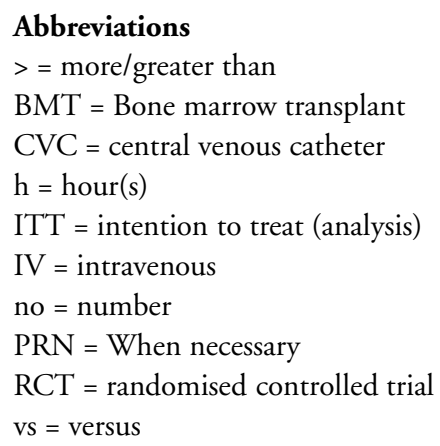

Characteristics of excluded studies [ordered by study ID]

\begin{tabular}{|c|c|}
\hline Study & Reason for exclusion \\
\hline Andersen 1986 & $\begin{array}{l}\text { Only the gauze and tape group had Nobecutan (verified with authors). One arm of the study had a co- } \\
\text { intervention with the dressing, as a result it was not possible to assess the effects of the dressing from those of } \\
\text { Nobecutan, the co-intervention }\end{array}$ \\
\hline Berggren 1995 & Reliability was not shown for outcomes. No further data regarding validity and reliability could be obtained \\
\hline Chico-Padron 2011 & CVCs were peripherally inserted and did not include outcomes of interest \\
\hline Conly 1989 & Outcome data not reported per patient group. No further data could be obtained \\
\hline Dickerson 1989 & $\begin{array}{l}\text { There was inadequate information to evaluate whether the study met the eligibility criteria, i.e. definition of } \\
\text { outcomes unclear. No further data could be obtained }\end{array}$ \\
\hline Freiberger 1992 & No data available. No further data could be obtained. \\
\hline Hägerström 1994 & There was inadequate information to evaluate whether the study was a randomised controlled trial \\
\hline Keenlyside 1992 & Outcomes not valid and reliable. \\
\hline Keenlyside 1993 & Later publication of excluded study Keenlyside 1992. \\
\hline Lawson 1986 & $\begin{array}{l}\text { Gauze and tape was compared with gauze and Tegaderm. } \\
\text { Duplicate publication of excluded study McCredie } 1984 .\end{array}$ \\
\hline Le Corre 2003 & Patients were not hospitalised. \\
\hline
\end{tabular}


(Continued)

\begin{tabular}{|c|c|}
\hline Little 1998 & "Standard" was not defined. Only the dry sterile dressing group had povidone-iodine ointment \\
\hline Maki 1984 & Outcome data not reported per patient group. No further data could be obtained \\
\hline Maki 1992 & Methodology unclear. No further data could be obtained. \\
\hline McCredie 1984 & $\begin{array}{l}\text { Gauze and tape was compared with gauze and Tegaderm. } \\
\text { Duplicate publication of Lawson } 1986 .\end{array}$ \\
\hline Nehme 1984 & Only the gauze and tape group had povidone-iodine ointment. \\
\hline Olson 2008 & Outcomes not valid and reliable. \\
\hline Petrosino 1988 & Outcome not valid and reliable. \\
\hline Powell 1982 & Only the gauze and tape group had povidone-iodine ointment. \\
\hline Powell 1984 & $\begin{array}{l}\text { Definition of catheter-related bloodstream infection and catheter colonisation differed from the review proto- } \\
\text { col. Duplicate publication of excluded study Powell } 1985 .\end{array}$ \\
\hline Powell 1985 & $\begin{array}{l}\text { Definition of catheter-related bloodstream infection and catheter colonisation differed from the review proto- } \\
\text { col. Duplicate publication of excluded study Powell } 1984 .\end{array}$ \\
\hline Reynolds 1987 & Patients were alternately allocated to groups. \\
\hline Ricard 1985 & $\begin{array}{l}\text { Results appear to have included data from patients with peripheral catheters. Also, outcome data were not } \\
\text { reported per patient. No further data could be obtained }\end{array}$ \\
\hline Thomas 1977 & Not clear how patients were allocated to groups. No further information could be obtained \\
\hline Wheeler 1988 & Historical controls. \\
\hline Young 1988 & Convenience allocation used. \\
\hline
\end{tabular}

\section{Abbreviations}

$\mathrm{CVC}=$ central venous catheter 
DATA AND ANALYSES

Comparison 1. Transparent polyurethane dressings versus gauze and tape

\begin{tabular}{|c|c|c|c|c|}
\hline Outcome or subgroup title & $\begin{array}{l}\text { No. of } \\
\text { studies }\end{array}$ & $\begin{array}{c}\text { No. of } \\
\text { participants }\end{array}$ & Statistical method & Effect size \\
\hline $\begin{array}{l}1 \text { Catheter-related blood stream } \\
\text { infection }\end{array}$ & 4 & 337 & Odds Ratio (M-H, Fixed, 95\% CI) & $4.19[1.02,17.23]$ \\
\hline 2 Exit-site infection & 3 & 265 & Odds Ratio (M-H, Fixed, 95\% CI) & $1.78[0.62,5.08]$ \\
\hline 3 Skin/site colonisation & 1 & & Odds Ratio (M-H, Fixed, 95\% CI) & Totals not selected \\
\hline 4 Positive catheter culture & 2 & 138 & Odds Ratio (M-H, Fixed, 95\% CI) & $0.74[0.27,2.09]$ \\
\hline 5 Tunnel infection & 1 & 101 & Odds Ratio (M-H, Fixed, 95\% CI) & $0.64[0.14,2.83]$ \\
\hline
\end{tabular}

Comparison 2. Transparent polyurethane dressings versus transparent polyurethane dressings

\begin{tabular}{lcccc} 
Outcome or subgroup title & $\begin{array}{c}\text { No. of } \\
\text { studies }\end{array}$ & $\begin{array}{c}\text { No. of } \\
\text { participants }\end{array}$ & Statistical method & Effect size \\
\hline $\begin{array}{l}1 \text { Catheter-related blood stream } \\
\text { infection }\end{array}$ & 1 & 101 & Odds Ratio (M-H, Fixed, 95\% CI) & $0.31[0.03,3.12]$ \\
\hline
\end{tabular}

\section{Analysis I.I. Comparison I Transparent polyurethane dressings versus gauze and tape, Outcome I Catheter-related blood stream infection.}

Review: Gauze and tape and transparent polyurethane dressings for central venous catheters

Comparison: I Transparent polyurethane dressings versus gauze and tape

Outcome: I Catheter-related blood stream infection

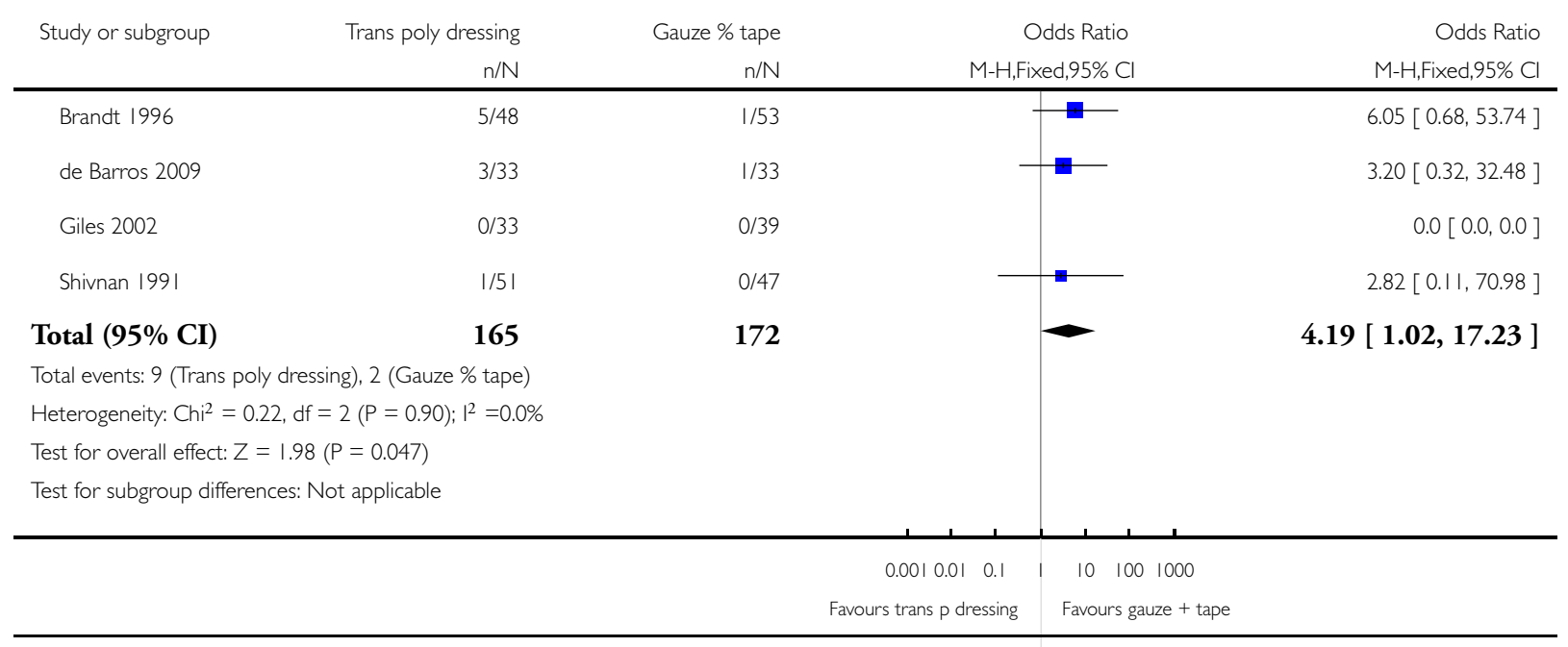




\section{Analysis I.2. Comparison I Transparent polyurethane dressings versus gauze and tape, Outcome 2 Exit-site infection.}

Review: Gauze and tape and transparent polyurethane dressings for central venous catheters

Comparison: I Transparent polyurethane dressings versus gauze and tape

Outcome: 2 Exit-site infection

\begin{tabular}{|c|c|c|c|c|c|}
\hline \multirow[t]{2}{*}{ Study or subgroup } & Trans poly dressing & Gauze \% tape & Odds Ratio & Weight & Odds Ratio \\
\hline & $n / N$ & $\mathrm{n} / \mathrm{N}$ & M-H,Fixed,95\% Cl & & M-H,Fixed,95\% Cl \\
\hline Brandt 1996 & $4 / 48$ & $2 / 53$ & - & $32.4 \%$ & $2.32[0.41,13.27]$ \\
\hline de Barros 2009 & $4 / 33$ & $3 / 33$ & & $49.0 \%$ & $1.38[0.28,6.71]$ \\
\hline Shivnan 1991 & $2 / 51$ & $1 / 47$ & 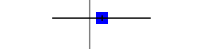 & $18.6 \%$ & $1.88[0.16,21.41]$ \\
\hline Total (95\% CI) & 132 & 133 & & $100.0 \%$ & $1.78[0.62,5.08]$ \\
\hline \multicolumn{6}{|c|}{ Total events: 10 (Trans poly dressing), 6 (Gauze \% tape) } \\
\hline \multicolumn{6}{|c|}{ Heterogeneity: $\mathrm{Chi}^{2}=0.19, \mathrm{df}=2(P=0.91) ;\left.\right|^{2}=0.0 \%$} \\
\hline \multicolumn{6}{|c|}{ Test for overall effect: $Z=1.07(P=0.28)$} \\
\hline \multicolumn{6}{|c|}{ Test for subgroup differences: Not applicable } \\
\hline
\end{tabular}

Analysis I.3. Comparison I Transparent polyurethane dressings versus gauze and tape, Outcome 3 Skin/site colonisation.

Review: Gauze and tape and transparent polyurethane dressings for central venous catheters

Comparison: I Transparent polyurethane dressings versus gauze and tape

Outcome: 3 Skin/site colonisation

\begin{tabular}{|c|c|c|c|c|}
\hline \multirow[t]{2}{*}{ Study or subgroup } & Trans poly dressing & Gauze \% tape & Odds Ratio & Odds Ratio \\
\hline & $\mathrm{n} / \mathrm{N}$ & $\mathrm{n} / \mathrm{N}$ & M-H,Fixed,95\% Cl & M-H,Fixed,95\% Cl \\
\hline Giles 2002 & 1/33 & $2 / 39$ & - & $0.58[0.05,6.68]$ \\
\hline
\end{tabular}


Analysis I.4. Comparison I Transparent polyurethane dressings versus gauze and tape, Outcome 4 Positive catheter culture.

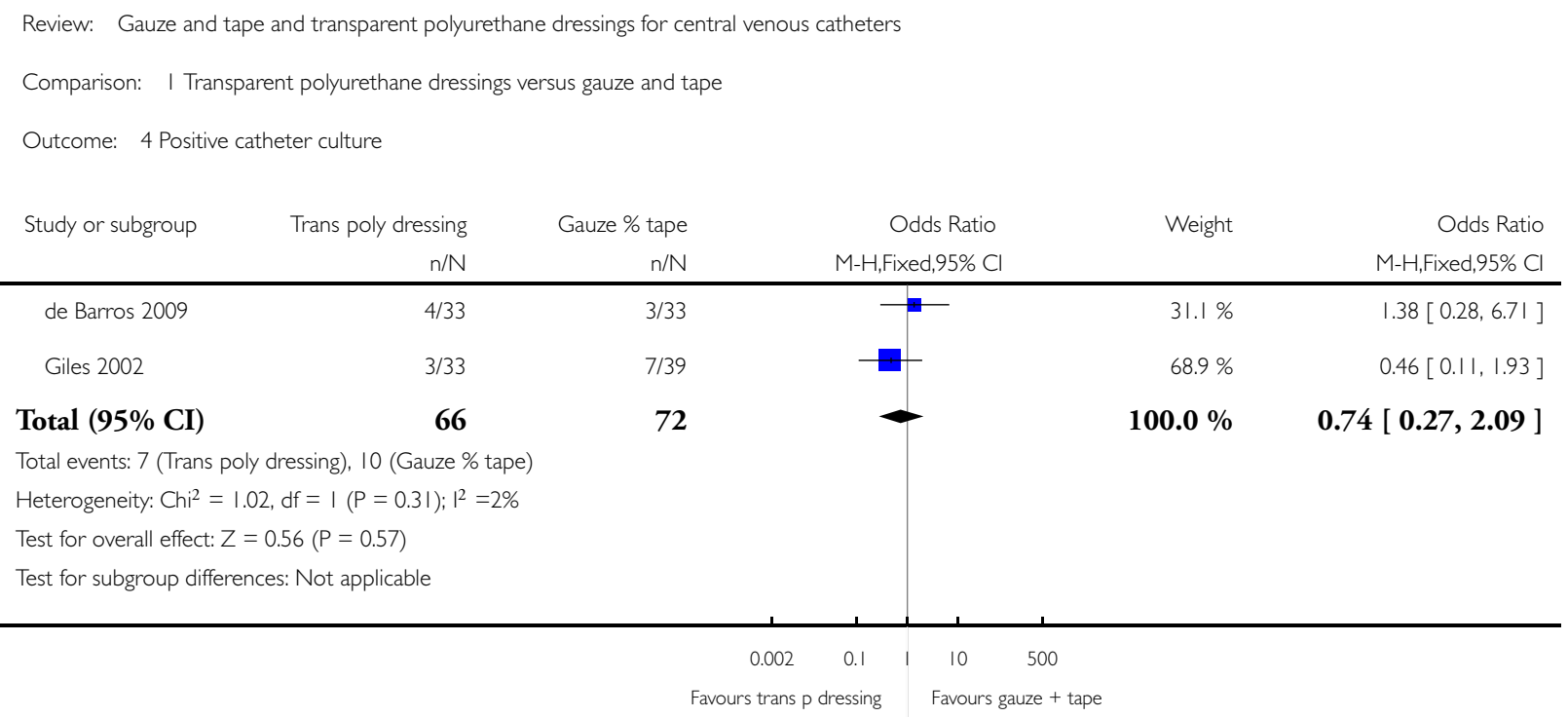

Analysis I.5. Comparison I Transparent polyurethane dressings versus gauze and tape, Outcome 5 Tunnel infection.

Review: Gauze and tape and transparent polyurethane dressings for central venous catheters

Comparison: I Transparent polyurethane dressings versus gauze and tape

Outcome: 5 Tunnel infection

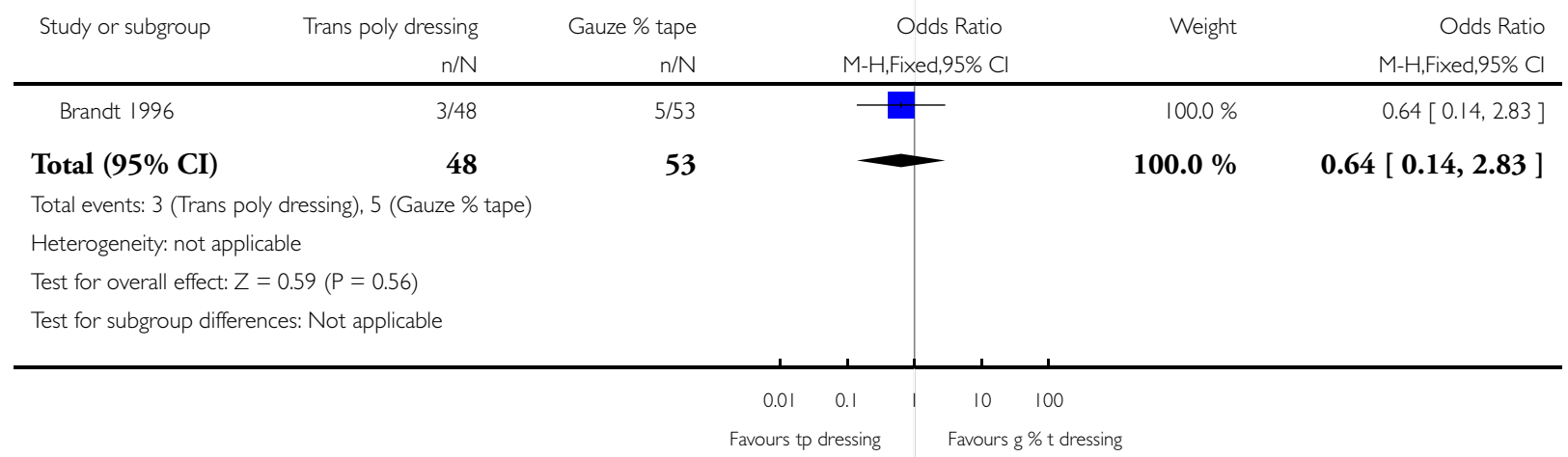


Analysis 2.I. Comparison 2 Transparent polyurethane dressings versus transparent polyurethane dressings, Outcome I Catheter-related blood stream infection.

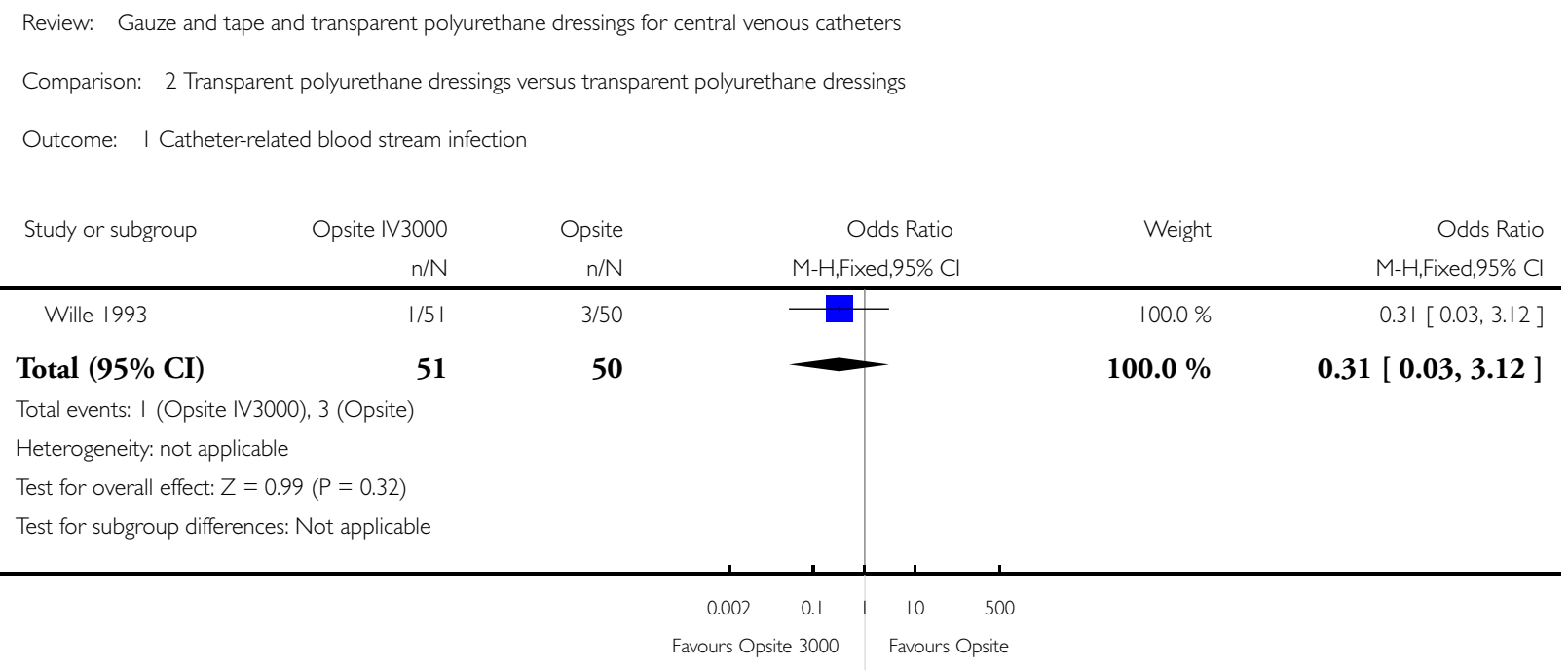

\section{A P PENDICES}

\section{Appendix I. Search strategies for the second update 2008}

\section{Search methods for identification of studies}

For the first update of this review in 2006, we searched The Cochrane Wounds Group Specialised Register (January 2006) and The Cochrane Central Register of Controlled Trials (CENTRAL) (The Cochrane Library 2006, Issue 1).

For this second update in 2008 we searched the:

Cochrane Wounds Group Specialised Register (Searched 7 March 2008);

The Cochrane Central Register of Controlled Trials (CENTRAL) (The Cochrane Library 2008, Issue 1);

Ovid MEDLINE (1950 to February Week 4 2008);

Ovid EMBASE (1980 to 2008 Week 09);

Ovid CINAHL (1982 to February Week 4 2008).

\section{Cochrane Wounds Group Specialised Register search strategy}

((catheter* and venous) or (catheter* and central) or (central and venous and line*) or (hickman and catheter) or (broviac and catheter) or (cook and catheter)) and ((occlusive and dressing*) or (gauze and dressing*) or (tape and dressing*) or (polyurethane and dressing*) or (permeable and dressing ${ }^{*}$ ) or (transparent and dressing $\left.{ }^{*}\right)$ or (nonpermeable and dressing ${ }^{*}$ ) or tegaderm or opsite ) 


\section{CENTRAL search strategy}

1. CATHETERIZATION CENTRAL VENOUS single term (MeSH)

2. (catheter* and venous)

3. (catheter* near central)

4. (central and venous and line*)

5. (hickman and catheter)

6. (broviac and catheter)

7. (cook and catheter)

8. (\#1 or \#2 or \#3 or \#4 or \#5 or \#6 or \#7)

9. OCCLUSIVE DRESSINGS single term $(\mathrm{MeSH})$

10. (occlusive and dressing*)

11. (gauze and dressing*)

12. (tape and dressing*)

13. (polyurethane and dressing*)

14. (permeable and dressing*)

15. (transparent and dressing*)

16. (nonpermeable and dressing*)

17. tegaderm

18. opsite

19. (\#9 or \#10 or \#11 or \#12 or \#13 or \#14 or \#15 or \#16 or \#17 or \#18)

20. (\#8 and \#19)

No restrictions were made on the basis of date, language or publication status.

\section{Appendix 2. Ovid MEDLINE search strategy}

1 exp Catheterization, Central Venous/

2 (venous adj3 (catheter\$ or line\$)).ti,ab.

3 (central adj3 (catheter\$ or line\$)).ti,ab.

4 hickman catheter\$.ti,ab.

5 broviac catheter $\$$.ti,ab.

6 cook catheter $\$$.ti,ab.

7 or/1-6

8 exp Occlusive Dressings/

9 ((occlusive or gauze or tape or polyurethane or permeable or nonpermeable or non-permeable or transparent) adj3 dressing $\$$ ).ti,ab. 10 or/8-9

\section{Appendix 3. Ovid EMBASE search strategy}

1 exp Central Venous Catheter/

2 (venous adj3 (catheter\$ or line\$)).ti,ab.

3 (central adj3 (catheter\$ or line\$)).ti,ab.

4 hickman catheter\$.ti,ab.

5 broviac catheter $\$$.ti,ab.

6 cook catheter\$.ti,ab.

7 or/1-6

8 exp occlusive dressing/

9 ((occlusive or gauze or tape or polyurethane or permeable or nonpermeable or non-permeable or transparent) adj3 dressing $\$$ ).ti,ab. 10 or/8-9

117 and 10 


\section{Appendix 4. EBSCO CINAHL search strategy}

$\mathrm{S} 13 \mathrm{~S} 8$ and $\mathrm{S} 12$

$S 12 S 9$ or $S 10$ or $S 11$

S11 AB occlusive N3 dressing* or gauze N3 dressing* or tape or polyurethane N3 dressing* or permeable N3 dressing* or nonpermeable or non-permeable N3 dressing* or transparent N3 dressing*

S10 TI occlusive N3 dressing* or gauze N3 dressing* or tape or polyurethane N3 dressing* or permeable N3 dressing* or nonpermeable or non-permeable N3 dressing* or transparent N3 dressing*

S9 ( $\mathrm{MH}$ "Occlusive Dressings")

$\mathrm{S} 8 \mathrm{~S} 1$ or $\mathrm{S} 2$ or $\mathrm{S} 3$ or $\mathrm{S} 4$ or $\mathrm{S} 5$ or $\mathrm{S} 6$ or S7

S7 TI cook catheter* or AB cook catheter*

S6 TI broviac catheter* or AB broviac catheter*

S5 TI hickman catheter* or AB hickman catheter*

S4 TI ( central N3 catheter* or central N3 line*) or AB ( central N3 catheter* or central N3 line*)

$\mathrm{S} 3 \mathrm{TI}$ ( venous N3 catheter* or venous N3 line*) or AB ( venous N3 catheter* or venous N3 line*)

S2 (MH "Central Venous Catheters+")

S1 (MH "Catheterization, Central Venous+")

\section{Appendix 5. Risk of bias criteria}

\section{Was the allocation sequence randomly generated?}

\section{Low risk of bias}

The investigators describe a random component in the sequence generation process such as: referring to a random number table; using a computer random number generator; coin tossing; shuffling cards or envelopes; throwing dice; drawing of lots.

\section{High risk of bias}

The investigators describe a non-random component in the sequence generation process. Usually, the description would involve some systematic, non-random approach, for example: sequence generated by odd or even date of birth; sequence generated by some rule based on date (or day) of admission; sequence generated by some rule based on hospital or clinic record number.

\section{Unclear}

Insufficient information about the sequence generation process to permit judgement of low or high risk of bias.

\section{Was the treatment allocation adequately concealed?}

\section{Low risk of bias}

Participants and investigators enrolling participants could not foresee assignment because one of the following, or an equivalent method, was used to conceal allocation: central allocation (including telephone, web-based and pharmacy-controlled randomisation); sequentially-numbered drug containers of identical appearance; sequentially-numbered, opaque, sealed envelopes.

\section{High risk of bias}

Participants or investigators enrolling participants could possibly foresee assignments and thus introduce selection bias, such as allocation based on: using an open random allocation schedule (e.g. a list of random numbers); assignment envelopes were used without appropriate safeguards (e.g. if envelopes were unsealed or non opaque or not sequentially numbered); alternation or rotation; date of birth; case record number; any other explicitly unconcealed procedure. 


\section{Unclear}

Insufficient information to permit judgement of low or high risk of bias. This is usually the case if the method of concealment is not described or not described in sufficient detail to allow a definite judgement, for example if the use of assignment envelopes is described, but it remains unclear whether envelopes were sequentially numbered, opaque and sealed.

\section{Blinding - was knowledge of the allocated interventions adequately prevented during the study?}

\section{Low risk of bias}

Any one of the following.

- No blinding, but the review authors judge that the outcome and the outcome measurement are not likely to be influenced by lack of blinding.

- Blinding of participants and key study personnel ensured, and unlikely that the blinding could have been broken.

- Either participants or some key study personnel were not blinded, but outcome assessment was blinded and the non-blinding of others unlikely to introduce bias.

\section{High risk of bias}

Any one of the following.

- No blinding or incomplete blinding, and the outcome or outcome measurement is likely to be influenced by lack of blinding.

- Blinding of key study participants and personnel attempted, but likely that the blinding could have been broken.

- Either participants or some key study personnel were not blinded, and the non-blinding of others likely to introduce bias.

\section{Unclear}

Any one of the following.

- Insufficient information to permit judgement of low or high risk of bias.

- The study did not address this outcome.

\section{Were incomplete outcome data adequately addressed?}

\section{Low risk of bias}

Any one of the following.

- No missing outcome data.

- Reasons for missing outcome data unlikely to be related to true outcome (for survival data, censoring unlikely to be introducing bias).

- Missing outcome data balanced in numbers across intervention groups, with similar reasons for missing data across groups.

- For dichotomous outcome data, the proportion of missing outcomes compared with observed event risk not enough to have a clinically relevant impact on the intervention effect estimate.

- For continuous outcome data, plausible effect size (difference in means or standardised difference in means) among missing outcomes not enough to have a clinically relevant impact on observed effect size.

- Missing data have been imputed using appropriate methods.

\section{High risk of bias}

Any one of the following.

- Reason for missing outcome data likely to be related to true outcome, with either imbalance in numbers or reasons for missing data across intervention groups.

- For dichotomous outcome data, the proportion of missing outcomes compared with observed event risk enough to induce clinically relevant bias in intervention effect estimate. 
- For continuous outcome data, plausible effect size (difference in means or standardised difference in means) among missing outcomes enough to induce clinically relevant bias in observed effect size.

- 'As-treated' analysis done with substantial departure of the intervention received from that assigned at randomisation.

- Potentially inappropriate application of simple imputation.

\section{Unclear}

Any one of the following.

- Insufficient reporting of attrition/exclusions to permit judgement of low or high risk of bias (e.g. number randomised not stated, no reasons for missing data provided).

- The study did not address this outcome.

\section{Are reports of the study free of suggestion of selective outcome reporting?}

\section{Low risk of bias}

Any of the following.

- The study protocol is available and all of the study's pre-specified (primary and secondary) outcomes that are of interest in the review have been reported in the pre-specified way.

- The study protocol is not available but it is clear that the published reports include all expected outcomes, including those that were pre-specified (convincing text of this nature may be uncommon)

\section{High risk of bias}

Any one of the following.

- Not all of the study's pre-specified primary outcomes have been reported.

- One or more primary outcomes is reported using measurements, analysis methods or subsets of the data (e.g. subscales) that were not pre-specified.

- One or more reported primary outcomes were not pre-specified (unless clear justification for their reporting is provided, such as an unexpected adverse effect).

- One or more outcomes of interest in the review are reported incompletely so that they cannot be entered in a meta-analysis.

- The study report fails to include results for a key outcome that would be expected to have been reported for such a study.

\section{Unclear}

Insufficient information to permit judgement of low or high risk of bias. It is likely that the majority of studies will fall into this category.

\section{Other sources of potential bias}

\section{Low risk of bias}

The study appears to be free of other sources of bias.

\section{High risk of bias}

There is at least one important risk of bias. For example, the study:

- had a potential source of bias related to the specific study design used; or

- had extreme baseline imbalance; or

- has been claimed to have been fraudulent; or

- had some other problem. 


\section{Unclear}

There may be a risk of bias, but there is either:

- insufficient information to assess whether an important risk of bias exists; or

- insufficient rationale or evidence that an identified problem will introduce bias.

\section{WHAT'S NEW}

Last assessed as up-to-date: 9 May 2011.

\begin{tabular}{|c|c|c|}
\hline Date & Event & Description \\
\hline 10 May 2011 & New search has been performed & $\begin{array}{l}\text { Third update, two new studies included (de Barros } 2009 \\
\text { Giles 2002) and two studies excluded (Chico-Padron } \\
\text { 2011; Olson 2008). In addition two previously included } \\
\text { studies were excluded, Hägerström } 1994 \text { because it was } \\
\text { judged not to be a RCT and Petrosino } 1988 \text { because } \\
\text { the outcome of 'infection' was not clearly defined or at- } \\
\text { tributed. The conclusions remain unchanged. Summary } \\
\text { of findings table completed }\end{array}$ \\
\hline
\end{tabular}

10 May 2011 New citation required but conclusions have not changed New authors added to the review team

\section{H I S T O R Y}

Protocol first published: Issue 3, 2002

Review first published: Issue 4, 2003

\begin{tabular}{lll}
\hline Date & Event & Description \\
\hline 14 April 2010 & Amended & Contact details updated. \\
\hline 11 November 2008 & Amended & Contact details updated \\
\hline 17 March 2008 & New search has been performed & $\begin{array}{l}\text { For this second update, new searches were carried out } \\
\text { in March 2008. Twenty-four citations were screened } \\
\text { but no new studies were identified for inclusion. The } \\
\text { review authors conclusions remain unchanged }\end{array}$ \\
\hline 17 March 2008 & Amended & Converted to new review format. \\
\hline 22 January 2006 & Newrch has been performed & $\begin{array}{l}\text { First update. The first update of this review was pub- } \\
\text { lished in the Cochrane Library, Issue 2, 2006. } \\
\text { For the first update, new searches were carried out } \\
\text { in January 2006. Three new studies were excluded }\end{array}$
\end{tabular}


from the review. The authors' conclusions remain unchanged

23 May $2003 \quad$ New citation required and conclusions have changed Substantive amendment. Review first published.

\section{CONTRIBUTIONSOFAUTHORS}

Joan Webster: risk of bias tables, data extraction, analysis, writing of 2011 update.

Donna Gillies: protocol development, data extraction, analysis, writing of original review and of all updates.

Claire Rickard: data extraction, writing of 2011 update.

Libba O'Riordan: protocol development, data extraction, analysis, writing of original review and of updates in 2006 and 2008.

Karen Sherriff: risk of bias tables, data extraction for 2011 update.

\section{Contributions of editorial base:}

Nicky Cullum: edited the review, advised on methodology, interpretation and review content. Approved the final review and review update prior to submission.

Sally Bell-Syer: coordinated the editorial process. Advised on methodology, interpretation and content. Edited and copy edited the review and the updated review.

Ruth Foxlee: designed the search strategy, ran the searches and edited the search methods section for the update.

\section{DECLARATIONS OF INTEREST}

None known.

\section{SOURCES OF SUPPORT}

\section{Internal sources}

- The Children's Hospital at Westmead, Sydney, Australia.

- The University of Sydney, Australia.

- Sydney West Area Health Service, Australia. 


\section{External sources}

- NIHR/Department of Health (England), (Cochrane Wounds Group), UK.

\section{N DEX TERMS}

\section{Medical Subject Headings (MeSH)}

*Occlusive Dressings; ${ }^{*}$ Polyurethanes; Bacterial Infections [* prevention \& control]; Catheterization, Central Venous [*adverse effects]; Randomized Controlled Trials as Topic

\section{MeSH check words}

Humans 